\title{
GEP analysis validates high risk MDS and acute myeloid leukemia post MDS mice models and highlights novel dysregulated pathways
}

Laura Guerenne ${ }^{1,2}$, Stéphanie Beurlet ${ }^{1,2}$, Mohamed Said ${ }^{3}$, Petra Gorombei ${ }^{1,2}$, Carole Le Pogam ${ }^{1,2}$, Fabien Guidez ${ }^{1,2}$, Pierre de la Grange ${ }^{4}$, Nader Omidvar ${ }^{5}$, Valérie Vanneaux ${ }^{6}$, Ken Mills ${ }^{7}$, Ghulam J Mufti ${ }^{3}$, Laure Sarda-Mantel ${ }^{8,9}$, Maria Elena Noguera ${ }^{10}$, Marika Pla ${ }^{1,2,11}$, Pierre Fenaux ${ }^{1,2,10}$, Rose Ann Padua ${ }^{1,2,10 \dagger}$, Christine Chomienne ${ }^{1,2,10 \dagger}$ and Patricia Krief ${ }^{1,2^{*}}$

\begin{abstract}
Background: In spite of the recent discovery of genetic mutations in most myelodysplasic (MDS) patients, the pathophysiology of these disorders still remains poorly understood, and only few in vivo models are available to help unravel the disease.
\end{abstract}

Methods: We performed global specific gene expression profiling and functional pathway analysis in purified Sca1+ cells of two MDS transgenic mouse models that mimic human high-risk MDS (HR-MDS) and acute myeloid leukemia (AML) post MDS, with NRASD12 and BCL2 transgenes under the control of different promoters ${ }_{\text {MRP }} \mathrm{NRASD} 12 /$ tet $^{\mathrm{hBCL}} \mathrm{C}$ or MRPS[NRASD12/hBCL-2], respectively.

Results: Analysis of dysregulated genes that were unique to the diseased HR-MDS and AML post MDS mice and not their founder mice pointed first to pathways that had previously been reported in MDS patients, including DNA replication/damage/repair, cell cycle, apoptosis, immune responses, and canonical Wnt pathways, further validating these models at the gene expression level. Interestingly, pathways not previously reported in MDS were discovered. These included dysregulated genes of noncanonical Wnt pathways and energy and lipid metabolisms. These dysregulated genes were not only confirmed in a different independent set of BM and spleen Sca1+ cells from the MDS mice but also in MDS CD34+ BM patient samples.

Conclusions: These two MDS models may thus provide useful preclinical models to target pathways previously identified in MDS patients and to unravel novel pathways highlighted by this study.

Keywords: Myelodysplastic syndrome, Mice models, Gene expression profile, MDS

\footnotetext{
* Correspondence: patricia.krief@inserm.fr

${ }^{\dagger}$ Equal contributors

'Université Paris-Diderot, Sorbonne Paris Cité, Institut Universitaire

d'Hématologie, Unité Mixte de Recherche (UMR-S) 1131, Paris, France

${ }^{2}$ Institut National de la Santé et de la Recherche Médicale (INSERM) Unité (U)

1131, Paris, France

Full list of author information is available at the end of the article
} 


\section{Background}

Myelodysplastic syndrome (MDS) is an hematopoietic stem cell disorder resulting in aberrant cell growth and differentiation with enhanced genomic instability. The diagnosis of MDS is based on morphological features (dysplasia) of the blood and bone marrow (BM) cells, cytopenias, frequent excess of marrow blasts, and specific cytogenetic abnormalities [1] such as deletions of chromosome 5, 7, and trisomy 8. Transformation to acute myeloid leukemia (AML) occurs in up to $40 \%$ of MDS patients [2]. Major advances have been acquired in the understanding of MDS pathogenesis. Along with refined risk stratification scores combining clinical and cytogenetic abnormalities, whole-genome sequencing (WGS) and next-generation sequencing (NGS) have identified mutations in genes involved in signal transduction, splicing machinery, and epigenetic or transcriptional pathways [3-11]. Gene expression profiling is a comprehensive approach taking into account the majority of these altered pathways and has contributed to a better definition of diagnosis and prognosis in many diseases including MDS, when combined with gene mutation or methylation data. [12-24]. Nevertheless, the survival of MDS patients, namely with high-risk MDS remains extremely poor and therapy options scarce.

Animal models expressing MDS associated gene phenocopy either the MDS disease or more often its risk of transformation to AML [25-27]. They have been instrumental to tackle other aspects of the disease such as the involvement of the microenvironment [28], and we have shown how they can be used to point at pathways to identify novel biomarkers and targeted therapies [29-35].

We therefore analyzed the gene expression pathways and ontology functional groups in Sca1+ cells from two MDS mouse models we have previously described [29, 30, 32-35].

These mice mimic human high-risk MDS (HR-MDS) or AML post MDS depending on the promoter driving the transgene (mutant NRASD12 or hBCL-2) expression $[32,35]$. BCL2 expression is required to drive the phenotype as inhibition of expression in conditional mice [32] or inhibition by $\mathrm{BH} 3$ mimetic inhibitors [29] reverts the phenotype. These models thus highlight the concept of non-oncogene addiction [36] where cells bearing the NRASD12 mutation require the BCL2 expression for survival and expansion. We have previously shown in these mice a concomitant increase in reactive oxygen species (ROS) with disease progression with a stepwise increase in the frequency of DNA damage leading to an increased frequency of error-prone repair of double-strand breaks (DSB) by nonhomologous end-joining [35]. The observed DNA damage and error-prone repair was decreased or reversed in vivo by $N$-acetyl cysteine antioxidant treatment [35], stressing the relevance of these mice models to relate genotype/phenotype to translational research. These models have already allowed to identify novel biomarkers of the disease in MDS patients such as the RAS:BCL-2 complex that links its localization at the plasma membrane or the mitochondria with the apoptosis features [30] and activates signaling protein profiles correlated with disease and progression to AML [29]. Both diseases are transplantable using BM or spleen cells from the diseased mice, and both transgenes are expressed at the stem cell level (Sca1+ compartment) [32]. Sca1- spleen cells had a much longer latency period before developing disease (Fig. 1e).

In this study, we found that the majority of the MDSdysregulated pathways that were unique to the MDS mice and not the founder mice were close to those reported in human MDS patients, underscoring the relevance of these two mice models as preclinical models.

\section{Results and discussion \\ Gene expression profile of the HR-MDS model}

Establishment and characteristics of the HR-MDS model are summarized in Fig. 1a-e. It is obtained by crossing two single transgenic mice, expressing two human genes known to be implicated in MDS, mutated NRASD12 and BCL2 (Fig. 1a). The clinical and biological features of these transgenic mice have already been described $[29,30,32-35]$, and the co-expression of the two transgenes is required to establish the HR-MDS disease and impact on survival, stressing the non-oncogenic addictive effect of the BCL2 expression (Fig. 1b). The main characteristics are pancytopenia, dysplasia, small percentage of blasts in the spleen and bone marrow (BM) (Fig. 1a, c), and increased apoptosis in the liver and spleen tissues by TUNEL [29] or by whole body SPECT using ${ }^{99} \mathrm{Tc}-$ Annexin [29] (Fig. 1d). The model has been validated to mimic the clinical (survival, response to treatment) and biological features of HR-MDS in patients [29, 30, 32-35]. A novel biomarker, the NRASD12 and BCL2 plasma membrane complex, correlates with apoptosis in spleen and BM cells in the HR-MDS mice [32] and with apoptosis and low blast counts in MDS patients [30] underscoring the relevance of this model to study human MDS.

Thus, to further exploit and complete the description of this HR-MDS model, we performed gene expression profile (GEP) analysis. GEP analysis was performed on RNA extracted from Sca1+ cells from HR-MDS mice, the founder mice (tethBCL2 and MRP8NRASD12) and normal FVB/N mice (Fig. 2a-c). Sca1+ spleen cells were chosen as we have shown that purified Sca1+ cells (from either the spleen or the BM of HR-MDS mice) (Fig. 1e) [32] can initiate the disease when transplanted in lethally irradiated syngenic FVB/N mice, and the spleen of these mice yields 


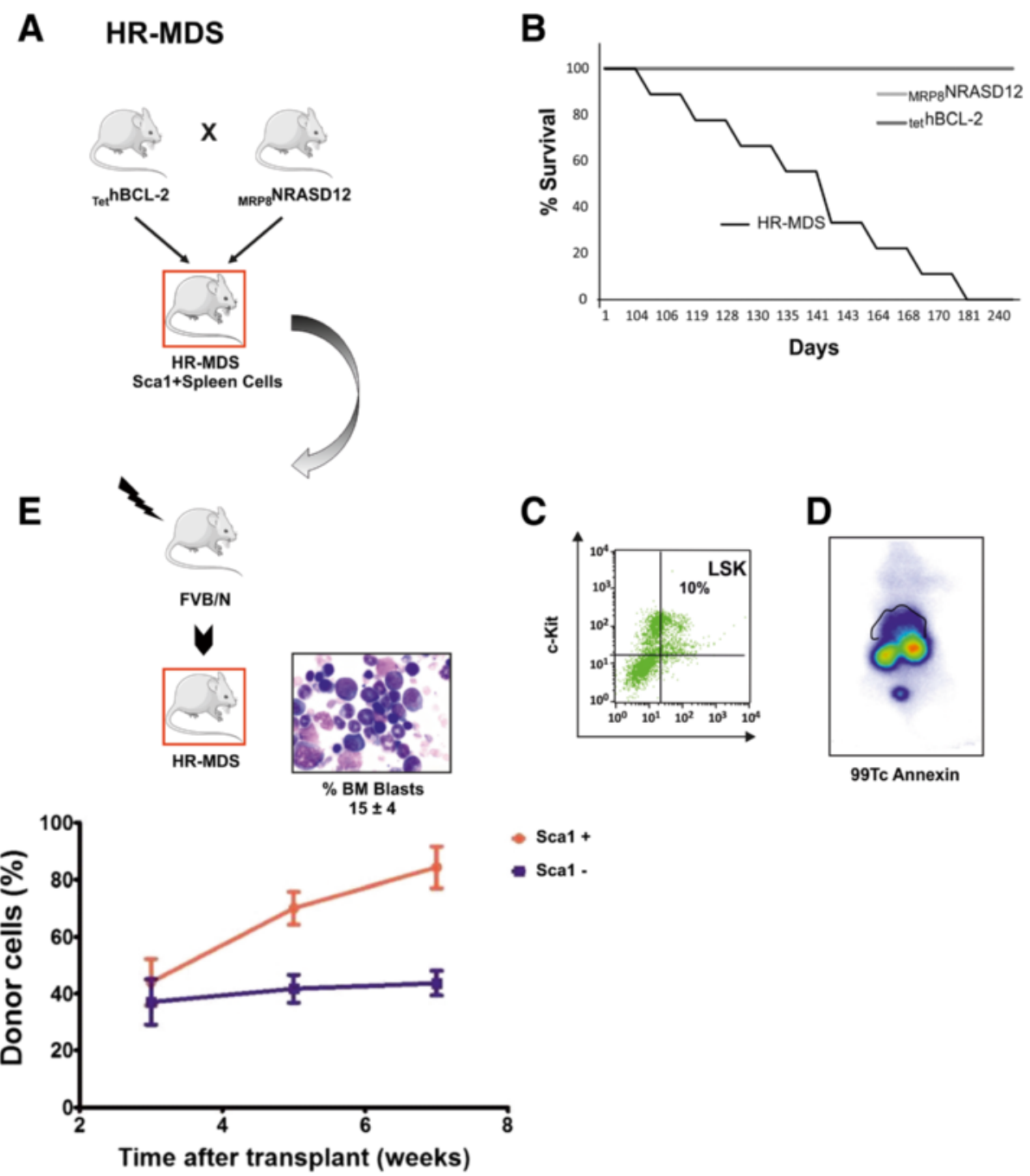

Fig. 1 a Schematic representation of the HR-MDS mouse model. The characteristics of this model have previously been published ${ }^{[24-26 ; 29]}$. $\mathbf{b}$ Decrease of the HR-MDS mice survival compared to its single transgenic mice founders, MRPs NRASD12 and tethBCL-2 transgenic mice; $\mathbf{c}$ Increased level of Lin-Sca1+-cKit+ (LSK) cells in the BM; $\mathbf{d}$ Increased apoptosis in the liver and spleen seen by whole body SPECT using ${ }^{99} \mathrm{~T}$ c-Annexin (liver and spleen region located above the kidneys); e The disease can be transplanted in normal FVB/N irradiated syngeneic mice with either the $\mathrm{Sca} 1+$ cells of the spleen or BM of the HR-MDS mice resulting in $15 \%$ blast infiltration in the BM blasts as in HR-MDS mice ${ }^{[24-26 ; 29]}$

more cells than the bone marrow, a prerequisite for both RNA quality and quantity for the subsequent analyses. GEP results were however validated on both spleen and bone marrow samples (Figs. 2e and 4). Compared to normal $\mathrm{FVB} / \mathrm{N}$ mice, 1641 genes were significantly dysregulated in HR-MDS mice, 1008 in the founder tet hBCL2 mice and 2232 in the ${ }_{\text {MRP }}$ NRASD12 mice. Fifty-six percent of these dysregulated genes were common and with similar levels of expression between the HR-MDS mice and its founders (MRP8NRASD12 and tethBCL2) and were not further analyzed in this study (Fig. 2a and Additional file 1: Table S1). Gene set enrichment analysis (GSEA) was performed with the 1641 genes significantly dysregulated in HR-MDS mice compared to normal $\mathrm{FVB} / \mathrm{N}$ mice, highlighting enrichment in cell metabolism (energy; lipid metabolism), cellular processes (DNA repair, cell cycle), angiogenesis, signal transduction, and immune system (Table 1 and Additional file 2: Figure S1A).

To select differentially expressed pathways implicated in the initiation or maintenance of the disease, we focused our study on a Database for Annotation, Visualization and Integrated Discovery (DAVID) GEP analysis performed on the 699 dysregulated genes that were unique to the HRMDS mice (Fig. 2a and Additional file 1: Table S2) and the few dysregulated genes $(n=16)$ that were differentially expressed (i.e., upregulated in the HR-MDS and downregulated in the founder mice and vice versa) (Fig. $2 \mathrm{~d}$ and Additional file 1: Table S3). Kyoto Encyclopedia of Genes and Genomes (KEGG) pathway analysis was performed using DAVID. The results are detailed in the 


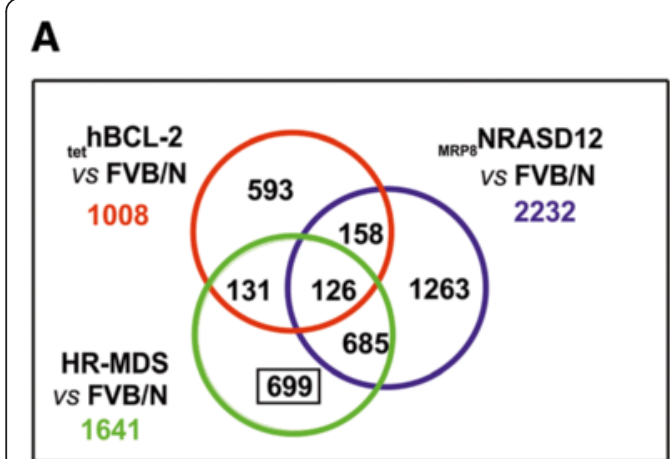

B

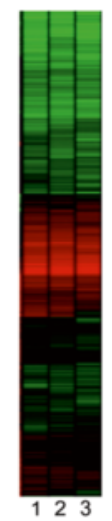

HR-MDS vs control FVB/N

C

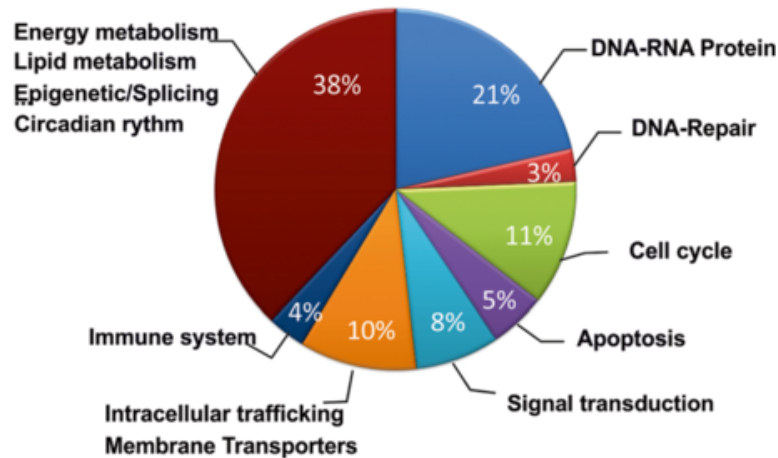

D
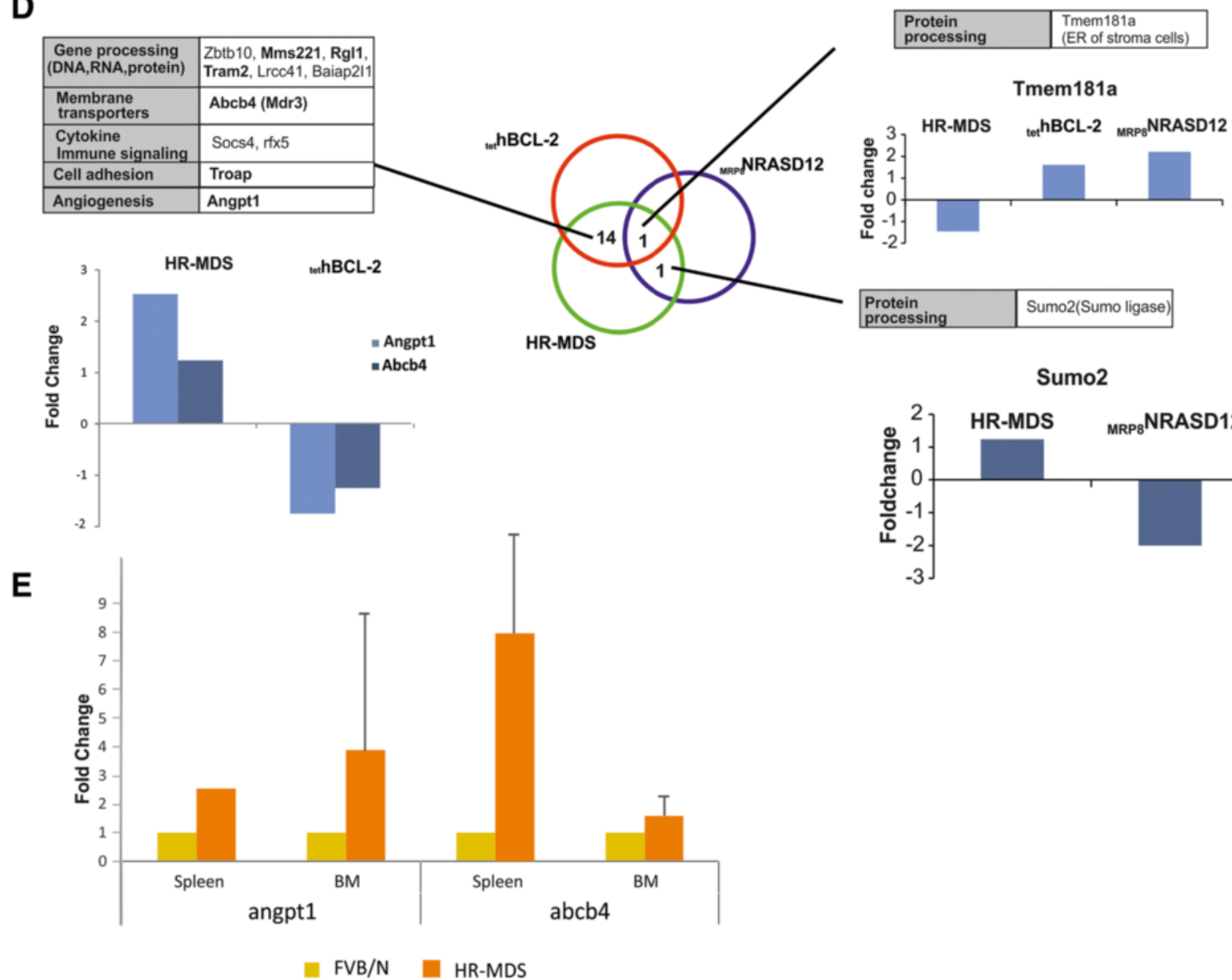

HR-MDS processing

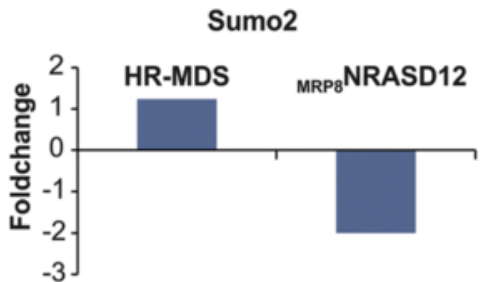

Fig. 2 a Venn diagrams of co-expressed and uniquely dysregulated genes compared to control FVB/N mice in the HR-MDS, MRP8NRASD12, and tet $\mathrm{hBCL}-2$ transgenic mice; $\mathbf{b}$ Heat map of the down- and upregulated genes performed on the Scal+ cells of HR-MDS $(n=3)$ compared to control FVB/N ( $n=3)$ mice; c Distribution in \% of the significantly dysregulated genes in the KEGG David annotation pathways; $\mathbf{d}$ Analysis of the differentially expressed genes (i.e., upregulated in the HR-MDS transgenic mice and downregulated in the founder mice and vice versa). Genes in regular font are expressed at lower levels and genes in bold font are expressed in higher levels. Examples of microarray data are shown for each intersection; e Validation of microarray data. qRT-PCR fold change of angpt1 and abcb4 gene expression in the BM and spleen cells of a different set of HR-MDS mice 
Table 1 Summary of the top pathways highlighted by GSEA on the total differentially expressed genes

\begin{tabular}{ll}
\hline HR-MDS versus FVB/N & AML post MDS versus FVB/N \\
\hline Adipogenesis & Adipogenesis \\
Androgen response & Allograft rejection \\
Angiogenesis & Androgen response \\
Bile acid metabolism & Apical junction \\
Coagulation & Bile acid metabolism \\
Complement & Cholesterol homeostasis \\
E2F targets & Coagulation \\
Estrogen response late & Complement \\
Fatty acid metabolism & E2F targets \\
G2M checkpoint & epitheliall mesenchymal transition \\
Glycolysis & G2M checkpoint \\
Kras signaling & Glycolysis \\
Mitotic spindle & Hedgehog-signaling \\
mTORC1 signaling & Mitotic spindle \\
Myc targets & Oxidative phosphorylation \\
Oxidative phosphorylation & Pancreas beta cells \\
UV response-dn & Spermatogenesis \\
Xenobiotic metabolism & Xenobiotic metabolism
\end{tabular}

Italicized data indicate pathways in common between the two models; Bold data indicate similar pathways found in the " unique " genes

Additional file 1: Tables S4-S14. The most significantly dysregulated genes were distributed into eight pathways (Fig. 2c). These dysregulated pathways included gene processing (namely DNA-RNA-protein processing) (Additional file 1: Table S4), cellular processes (DNA repair, cell cycle, survival/apoptosis) (Additional file 1: Tables S5-S7), signal transduction (Additional file 1: Tables S8 and S9), intracellular trafficking and membrane transporters (Additional file 1: Table S10), and immune system (Additional file 1: Table S11). Finally, around $38 \%$ of dysregulated pathways concerned various pathways but with less genes involved per pathway including energy and lipid metabolisms (Additional file 1: Table S12), and epigenetic/splicing pathways (Additional file 1: Table S13)

Of the ten most significantly upregulated pathways (Table 2), the pathway ranking first concerned genes of the PSM family of the proteasome, namely genes coding for different components of 26S. Increase in proteasome activity has been reported in MDS patients, and various studies have shown the potential benefit of combining an inhibitor of proteasome, bortezomid, with conventional MDS therapy [37, 38]. Equally significantly upregulated were genes coding for cell metabolism (energy and lipids) and the cell cycle/checkpoints/DNA repair. Genes coding for components of the major complexes of the mitochondrial electron transport chain were also significantly upregulated (Fig. 3a). These included genes of complex I:
NADH deshydrogenase, complex IV: cytochrome c oxidase, and complex V: ATPase (confirmed by quantitative reverse transcription-PCR (qRT-PCR) in the BM and spleen cells of HR-MDS mice Fig. 4). Oxidative phosphorylation is the metabolic pathway in which mitochondria produce ATP required by proliferating cells. Oxidative metabolism also produces reactive oxygen species (ROS) such as superoxide and hydrogen peroxide, leading to propagation of free radicals, enhancement of antioxidant pathways but also DNA damage. Genes of the ROS/ antioxidant pathways (such as Txn1, Gpx1, Cebpo) were not significantly dysregulated in the HR-MDS mice compared to the founder mice (Additional file 1: Table S14), whereas cell cycle checkpoints, DNA damage/repair genes were significantly upregulated (i.e., $\operatorname{mad} 2 l 1, c d c 25 a$, $m d m 2$, chek2, rad54b, brca1, fancm (Table 2, Additional file 1: Tables S5 and S7). These pathways and genes have also been shown altered in some GEP studies of MDS patients $[12,16]$. Amongst the lipid metabolism upregulated genes figured both those of ether lipid metabolism and glycosphingolipid biosynthesis. Though increase of acylglycerophospholipids and ether lipid metabolism have been reported in cancers, (confirmed by qRT-PCR in the BM and spleen cells of HR-MDS mice Fig. 4) with loss of tumorigenicity when efficiently targeted [39], little is known regarding MDS patients.

A survival/apoptosis pathway showed a significant downregulation of genes coding for inhibitors of apoptosis (naip, tnfaip3, and madk9) in line with the apoptosis observed in this HR-MDS model [29, 30, 32]. Downregulation of genes of the PI3K family (class II) and Pten was also significantly downregulated (Table 3). While Pten is a well-known tumor suppressor, few reports link it with MDS [40, 41]. Class II PI3K proteins are involved in the translocation of proteins to the cell membrane and have been shown instrumental in Shh signaling, a pathway implicated in the relation of stem cell with its environment [42]. Moreover, two other downregulated pathways included genes coding for socs 4 , a member of the suppressor of cytokine signaling family (confirmed by qRT-PCR in the BM and spleen cells of HR-MDS mice Fig. 4), and regulators of the immune response such as CD19 and CD40, also reported to be decreased in MDS [20, 22, 43]

When we separately studied the 16 genes that were differentially expressed between the HR-MDS mice and its founder single transgenic mice (i.e., upregulated in the HR-MDS and downregulated in the founders or vice versa), we found that the majority (14 out of 16) of these differentially regulated genes were between the HR-MDS and the founder tet hBCL-2 mice (Fig. $2 \mathrm{~d}$ and Additional file 1 : Table S3). The most significantly differentially dysregulated gene was angiopoietin, Angpt1, upregulated in the HR-MDS mice (confirmed by qRT-PCR in the BM and spleen cells of HR-MDS mice and CD34+ from 
Table 2 Top regulated pathways in the list of upregulated genes in HR-MDS mice

\begin{tabular}{|c|c|c|c|}
\hline Functional pathway KEGG database & $n$ & Up $P$ value & Upregulated genes $^{a}$ \\
\hline \multirow[t]{3}{*}{ Genetic information processing Proteasome } & 7 & $4.3 \mathrm{E}-04$ & PSMD14, PSMD12, PSMC4, PSMA5, PSMD2, POMP, PSME4 \\
\hline & & & $\begin{array}{l}\text { PSMD14, PSMD12, PSMC4, PSMA5, PSMD2, PSME4 : PSM family } \\
\text { (proteasome } 265 \text { subunit) }\end{array}$ \\
\hline & & & POMP: proteasome maturation protein \\
\hline \multirow[t]{7}{*}{ Energy Metabolism Oxidative phosphorylation } & 10 & $2.0 \mathrm{E}-03$ & $\begin{array}{l}\text { NDUFB3, NDUFV2, ATP5C1, COX4I2, COX4I1, VDAC2, VDAC3, } \\
\text { ATP5J, SLC25A4, PPID }\end{array}$ \\
\hline & & & NDUFB3, NDUFV2: NADH Ubiquinone oxido reductase \\
\hline & & & ATP5C1, ATP5): one of the subunits of mitochondria APTase \\
\hline & & & VDAC2, VDAC3: voltage dependent anion channel. \\
\hline & & & COX412, COX411 cytochrome c oxidase subunit 4 \\
\hline & & & SLC25A4: SOLUTE CARRIER FAMILY 25 mitochondrial ADP/ATP translocator \\
\hline & & & PPID: peptidylprolyl isomerase D \\
\hline \multirow[t]{5}{*}{ Lipid metabolismEther lipid metabolism } & 4 & $3.7 \mathrm{E}-02$ & PAFAH1B3, AGPAT4, PPAP2A, CHPT1 \\
\hline & & & PAFAH1B3: platelet-activating factor acetylhydrolase 16 , catalytic subunit 3 \\
\hline & & & AGPAT4: 1-acylglycerol-3-phosphate O-acyltransferase 4 \\
\hline & & & PPAP2A: Phosphatidic Acid Phosphatase $2 a$ \\
\hline & & & CHPT1: choline phosphor transferase 1 \\
\hline \multirow[t]{4}{*}{ Lipid metabolism Glycosphingolipid biosynthesis } & 3 & $3.9 \mathrm{E}-02$ & SLC33A1, HEXB, GLB1 \\
\hline & & & SLC33A1: solute carrier family 33 (acetyl-CoA transporter) \\
\hline & & & HEXB: hexosaminidase B (beta polypeptide) \\
\hline & & & GLB1 : Galactosidase, beta 1 \\
\hline \multirow[t]{5}{*}{ Cellular processesCell cycle } & 7 & $5.4 \mathrm{E}-02$ & MAD2L1, CCNH, SKP2, MDM2, CHEK2, CDC25A, BUB3 \\
\hline & & & MAD2L1, mitotic spindle assembly checkpoint (interacts with BUB1) \\
\hline & & & CCNH: cyclin H; SKP2 : S-phase kinase-associated protein 2 \\
\hline & & & $\begin{array}{l}\text { MDM2: mouse double minute } 2 \text { homolog (E3 ubiquitin-protein ligase); } \\
\text { CHEK2: checkpoint }\end{array}$ \\
\hline & & & BUB3: budding uninhibited by benzimidazole (checkpoint protein) \\
\hline
\end{tabular}

aGene card nomenclature

MDS patients Figs. 2e and 4). Angiogenesis in MDS has been described, and some of the efficacy of Lenalidomide is related to its anti-angiogenic effect [44, 45]. The other dysregulated genes were linked to gene processing with transcription regulation genes such as Zbtb10 (a Zinc finger/POZ domain gene), the $M m s 22 \mathrm{l}$ gene (a stabilizer of the NFKB-like enhancer), the $R g l 1$ gene (the Ral guanine nucleotide dissociation stimulator involved in Ras and Ral signaling [46]), the Lrrc41 gene coding for a substrate of RhoBTB-dependent cullin 3 ubiquitin ligase complexes [47], and the Baiap $2 l 1$ gene that modulates MDM2-mediated p53 low-level ubiquitination. This latter gene is dysregulated in myelofibrosis and a fusion partner of Fgfr3 in AML [48] membrane transporters with an increased expression of the P-glycoprotein gene $(A b c b 4-M d r 3)$ in the HR-MDS mice, gene linked to drug resistance in MDS [49] (confirmed by qRT-PCR in the $\mathrm{BM}$ and spleen cells of HR-MDS mice Fig. 4), cytokine signaling (Socs4, and $R f x 5$, a regulatory factor for major histocompatibility complex, altered in primary $\mathrm{MHCI}$ deficiency [50]) and cell adhesion with the Troap gene coding for the trophin-associated protein involved in cell adhesion complexes [51]. Only one gene, Sumo2 (coding for a SUMO ligase) was significantly differentially expressed (upregulated) between the HR-MDS mice and its founder ${ }_{\text {MRP }}$ NRASD12 mice; SUMOylation is a major post translation modification of key proteins involved in cell control and carcinogenesis [52]. Finally, only one gene, Tmem181a, was differentially expressed between HR-MDS and its two founders, MRP8NRASD12 and tet hBCL-2 mice (upregulated in the founders and downregulated in HR-MDS mice). The function of Tmem181a is still not fully defined; it is a transmembrane protein with a conserved domain of Wnt binding factor required for Wnt secretion MIG-14 [53]. Abnormalities in the microenvironment and Wnt signaling may well relate to our current knowledge of MDS disease initiation and/or maintenance [54]. 


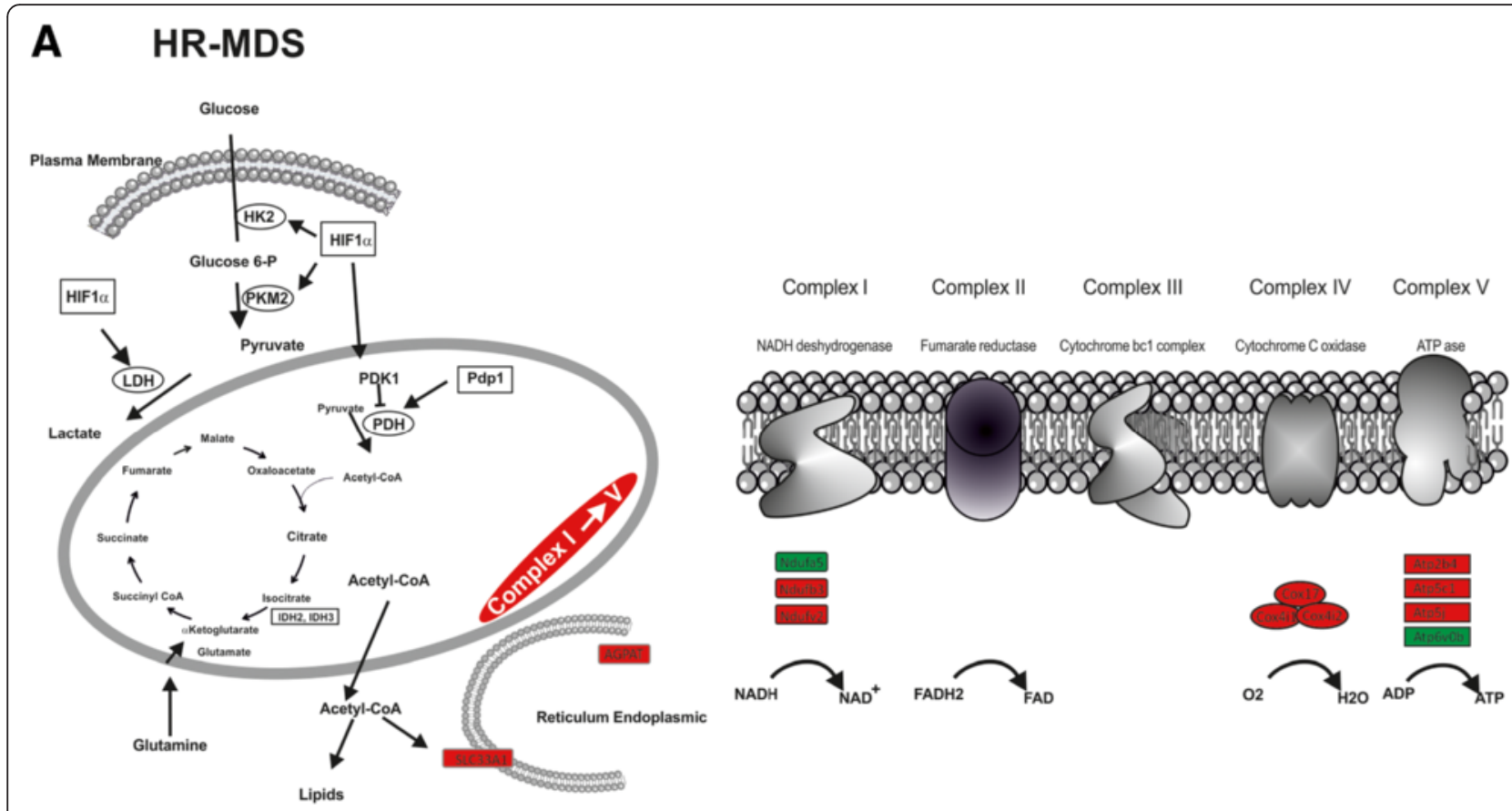

\section{B AML post MDS}
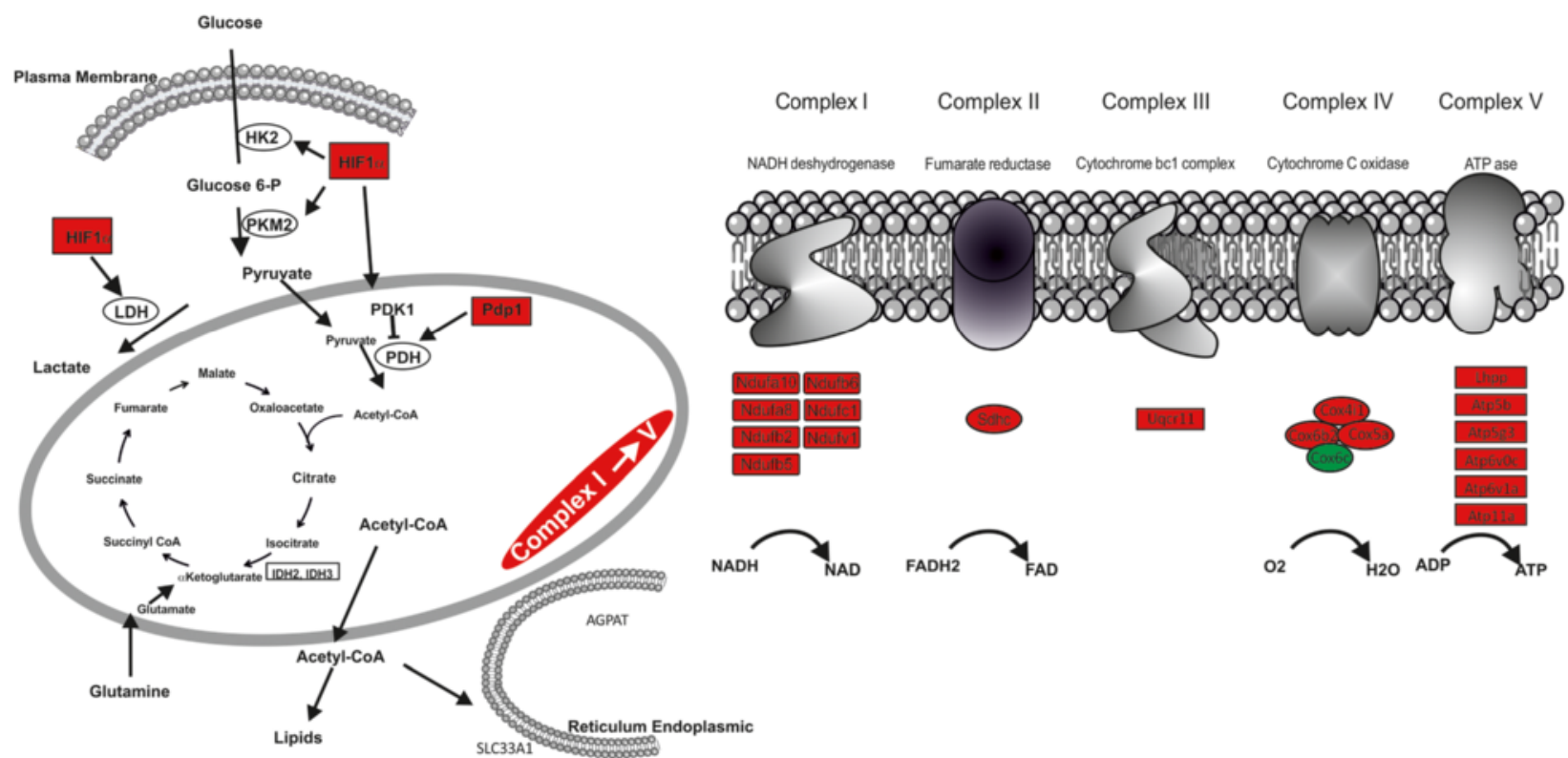

Fig. 3 Schematic representation of dysregulated energy metabolism pathways. Dysregulated pathways are noted in red, if upregulated, and in green, if downregulated. a HR-MDS; b AML post MDS

Gene expression profile of the AML post MDS model

The same GEP and functional annotation studies were performed in the AML post MDS model. The characteristics of the AML post MDS model are summarized in Fig. 5. The only difference in the establishment of the AML post MDS mice compared to that of the HR-MDS mice is the founder BCL2 mice where the promoter driving the expression of the BCL2 transgene is MRP8 (Fig. 5a). The AML post MDS mice have been described with the HR-MDS mice $[29,30,32-35]$. The coexpression of the two transgenes is required to establish the HR-MDS disease and impacts on survival (Fig. 5b). The AML post MDS mice present features of AML with major infiltration of blasts in the BM (Fig. 5a) and spleen, 


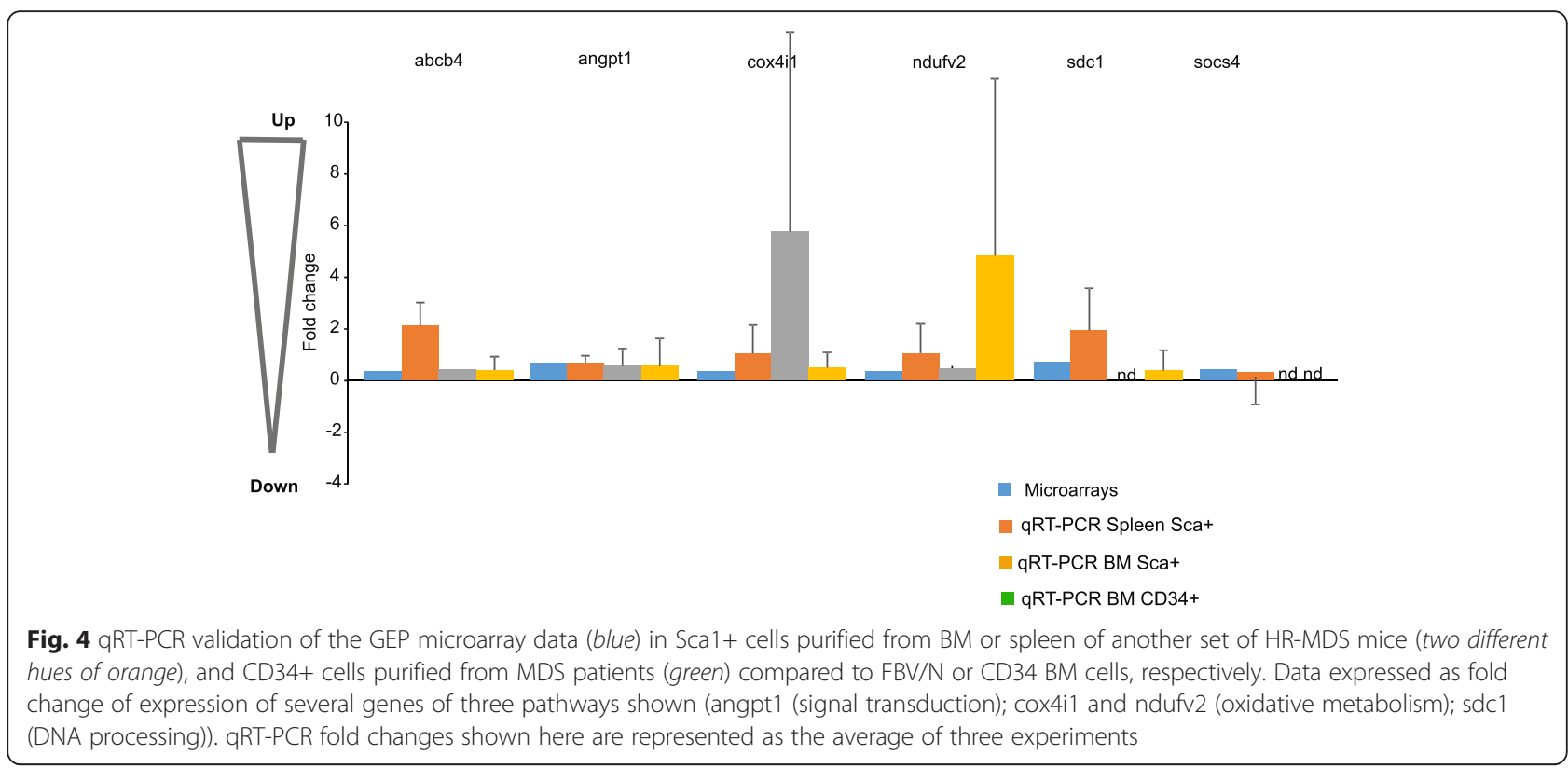

a significant increase of immature cells $\mathrm{Lin}^{-} \mathrm{Sca} 1+\mathrm{ckit}+$ (LSK) cells in the BM (Fig. 5c) and absence of apoptosis by Tunel assay [29] and 99Tc-Annexin SPECT imaging (Fig. 5d). Persistence of dysplasia in myeloid cells confers the title of AML post MDS to the disease [25, 32]. We have previously shown in these mice an increase in reactive oxygen species (ROS) and the frequency of DNA damage [35]. Contrary to the HR-MDS mice, but in line with the leukemic features of these mice, the RAS:BCL2 complex, is here found at the mitochondria membrane, favoring BCL2 pathways and increased survival of blast cells [32]. The mitochondrial localization of the RAS:BCL2 complex was also noted in MDS patients with high blast count and low levels of apoptosis [30]. As for the HR-MDS

Table 3 Top regulated pathways in the list of downregulated genes in HR-MDS mice

\begin{tabular}{llll}
\hline Functional pathway KEGG database & $n$ & Down $P$ value & Downregulated genes $^{\text {a }}$ \\
\hline Cellular processes Inhibition of Apoptosis & 5 & $1.2 \mathrm{E}-2$ & NAIP6, NAIP5, NLRC4, MAPK9, TNFAIP3 \\
& & & NAIP6; NAIP5: NLR family, apoptosis inhibitory protein 6; NLRC4: NLR family \\
& & & CARD domain-containing protein 4; MAPK9: Mitogen activated kinase 9;
\end{tabular}

Environmental adaptation Circadian rhythm $\quad 3 \quad 1.4 \mathrm{E}-2$

Signal transduction Phosphatidylinositol signaling system $5 \quad 2.2 \mathrm{E}-2$

Human diseasesType II diabetes mellitus

Human diseasesPrimary immunodeficiency
$4 \quad 3.2 \mathrm{E}-2$

$3 \quad 9.3 \mathrm{E}-2$
TNFAIP3: Tumor necrosis factor, alpha-induced protein 3

\section{NR1D1, PER1, CLOCK}

NR1D1: nuclear receptor subfamily 1, group D, member 1

PER1: period circadian clock 1

CLOCK: circadian locomotor output cycles kaput

PIK3C2A, PIK3C2B, PIP4K2A, PTEN, ITPR1

PIK3C2A: phosphatidylinositol-4-phosphate 3-kinase

PIP4K2A: phosphatidylinositol-5-phosphate 4-kinase, type II,

PTEN: phosphatase and tensin homolog

ITPR1: inositol 1,4,5-trisphosphate receptor type 1

IRS2, MAPK9, CACNA1E, SOCS4

IRS2: insulin receptor substrate 2; MAPK9: mitogen activated kinase 9

CACNA1E: calcium channel, voltage-dependent, $R$ type, alpha $1 E$ subunit

SOCS4: suppressor of cytokine signaling 4

CD19, RFX5, CD40

CD19: antigen receptor of B lymphocytes; RFX5: regulatory factor $X$; CD40: TNF receptor superfamily member 5 
A AML post MDS

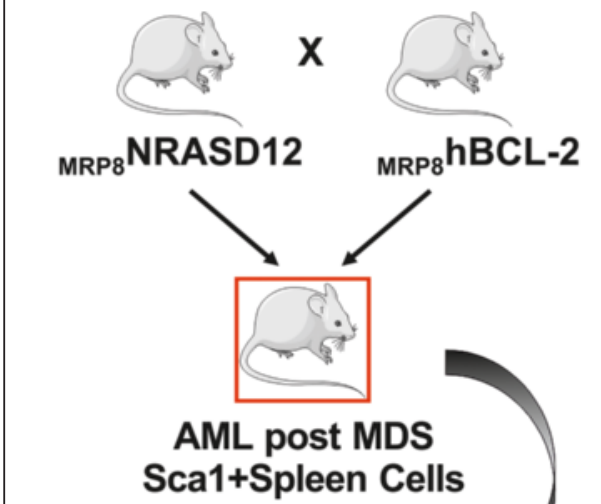

F

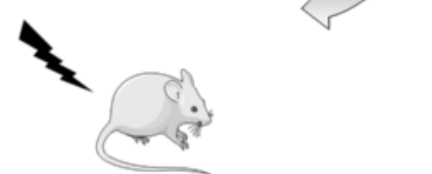

FVB/N

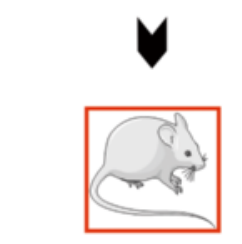

AML post MDS

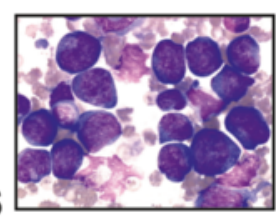

$\%$ BM Blasts

$54 \pm 3$
B

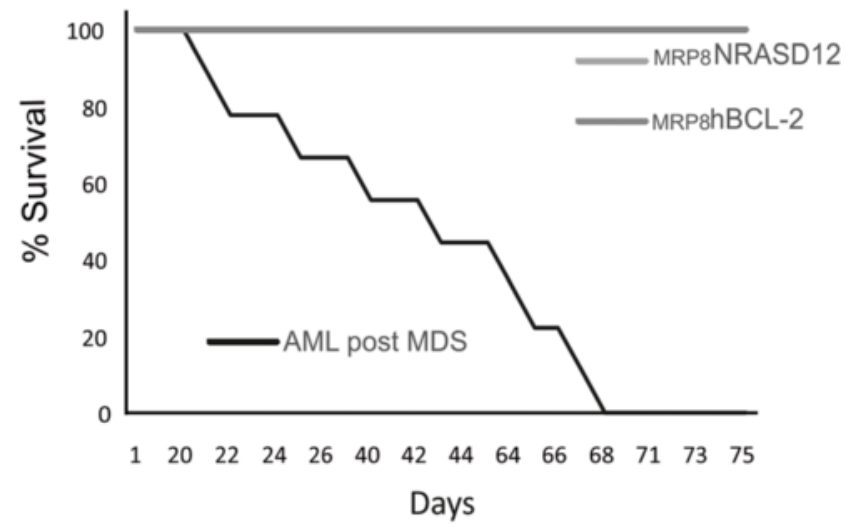

C
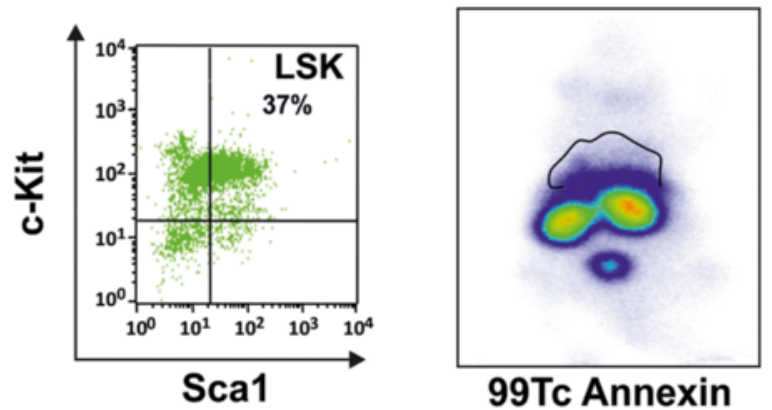

E

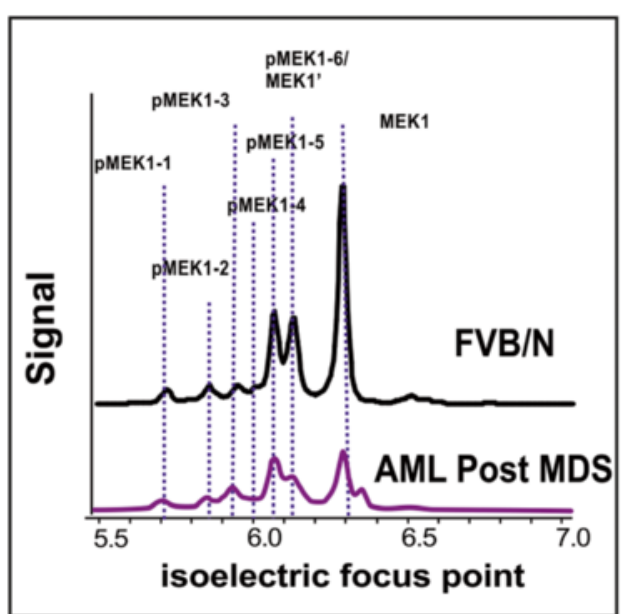

Fig. 5 a Schematic representation of the AML post MDS mouse model. The characteristics of these models have previously been published [24-26;29]; b Decrease of the survival of AML post MDS mice compared to the survival of the funders, MRP8NRASD12 and MRPs $_{\text {hBCL-2; }} \mathbf{c}$ Increased level of Lin-Sca1+-cKit+ (LSK) cells in the BM; d Decreased level of apoptosis in the liver by whole body SPECT using ${ }^{99}$ Tc-Annexin (liver and spleen region located above the kidneys); e Validation of microarray data: Decreased levels of MEK isoforms in the AML post MDS spleen cells compared to FVB/N control mice by the nanofluidic proteomic analysis; $\mathbf{f}$ The disease can be transplanted in normal FVB/N irradiated syngeneic mice with either the Sca1+ cells of the spleen or BM of the AML post MDS mice resulting in $54 \%$ blast infiltration in the BM blasts as in AML post MDS mice. ${ }^{[24-26 ; 29]}$ 
model, we have shown that injection of Sca1+ spleen cells from AML post MDS mice transfers the disease in syngeneic mice (Fig. 5f) [32].

The GEP of these mice shows a total of 8026 dysregulated genes compared to normal FVB/N mice (Fig. 6a, b), as most $(67 \%, n=5352)$ of these dysregulated genes were common and with similar levels of expression between the AML post MDS mice and the founders (the ${ }_{M R P 8}$ NRASD12 or the MRP 8 hBCL2 single transgenic mice) (Additional file 1: Table S15). Gene Set Enrichment Analysis (GSEA) was performed with the 8026 genes significantly dysregulated in AML post MDS mice compared with normal FVB/N mice, highlighting enrichment in cellular processes (cell cycle/DNA damage-repair), cell metabolism (energy; lipid metabolism), and immune system (Table 1 and Additional file 2: Figure S1B).

As for the HR-MDS model, to select differentially expressed pathways implicated in the initiation or maintenance of the disease, we focused our study on Database for Annotation, Visualization and Integrated Discovery (DAVID) GEP analysis, on the 2620 dysregulated genes that were unique to the AML post MDS mice (Additional file 1: Table S16) and the 54 dysregulated genes that were differentially expressed (i.e., upregulated in the AML post MDS and downregulated in the founder mice and vice versa) (Fig. 6d and Additional file 1: Table S17).

We first analyzed the 2620 genes unique to the AML post MDS mice (Additional file 1: Table S16). DAVID and KEGG functional annotation distributed the AML post MDS dysregulated genes in functions similar to those noted for the HR-MDS model, underscoring the malignant background of both models (Fig. 6c). Like the HR-MDS mouse, the majority of the genes were distributed in pathways implicated in gene processing (DNA-RNAprotein) (Additional file 1: Table S18), DNA-repair (Additional file 1: Tables S19), cellular processes (cell cycle (Additional file 1: Tables S20), survival/apoptosis (Additional file 1: Table S21), signal transduction (Additional file 1: Tables S22, S23), intracellular trafficking, membrane transporters (Additional file 1: Table S24)), and genes of the immune system (Additional file 1: Tables S25, S26). Other pathways included energy and lipid metabolism (Tables 4 and 5; Additional file 1: Table S28), kinases (Additional file 1: Table S23), Rho/Wnt pathway (Table 6 and Additional file 1: Table S23C), and genes of splicing and epigenetic enzymes (Additional file 1: Tables S18, S27).

KEGG analysis identified 13 significantly dysregulated pathways (Tables 4 and 5). The most upregulated pathway concerned cell metabolism (Table 4). Indeed, in this model, all the components of the oxidative phosphorylation pathway were upregulated (Fig. 3b) (complex I: $\mathrm{NADH}$ dehydrogenase, complex II: fumarate reductase, complex III: cytochrome bc1 complex, complex IV: cytochrome c oxidase, and complex V: ATPase). Amongst the other upregulated cell metabolism pathways were those of nucleotide/pyrimidine metabolism. The upregulation of these pathways are in line with the up regulation of other cellular processes pathways such as: cell cycle, DNA replication and repair (blm, rad18, rad51, rad54), and multiple histone family genes, signaling molecules and signal transduction (cytokine and cytokine receptors including Epo, chemokines, TNFs, JAK-STAT signaling), and the immune system with Toll receptor and interferon pathways. All these pathways find their place in the active leukemia features found in this mouse model and have to some extent been reported either in MDS or AML patients $[20,22,29,30,32-35,43]$. Interestingly, one study also highlighted the upregulation of histone genes coding for histones 2 and 1 in MDS patients [55].

Intriguingly, of the five most downregulated pathways (Table 5), three concern signal transduction pathways. The most significantly downregulated pathway was represented by numerous kinases of the MAPK (MEK) pathway (MAP2K1, MAPK2P2 MAKA4P2, MAP3K7). These MAPK genes also cluster in two functional annotation signal transduction pathways (signal transduction and pathways in cancer) with other enzymes or proteins acting downstream of environmental signaling such as $b m p, \operatorname{Tgf\beta }$, or $W n t$ signaling. We confirmed the decreased expression of one of these MAPK, MAP2K, at the protein level in another set of AML post MDS mice cells by nanofluidic proteomic immunoassay (Fig. 5e). The Wnt pathway (found in the annotation "cancer pathways") is the most targeted pathway with 23 dysregulated genes (Tables 4 and 6). Fourteen of these genes were downregulated (such as Dvl, Ppp3ca, Csnk1a1, Smad4, Rock1) while two genes coding for inhibitors of Wnt signaling, Icat (Ctnnbip1) and Disabled (Dab2) were upregulated (the latter by nearly sevenfold). Other pathways pointed to a potential dysfunction of interaction with the environment, such the Rho signaling pathway (Additional file 1: Table S23C) and the CD44 gene (Table 6). The downregulation of the Wnt canonical pathway has already been underscored in several studies in MDS patients [14, 19, 20, 22, 24, 56, 57]. However, our analysis also highlights that genes of the noncanonical Wnt pathway (Rock1, Can, Ppp3ca, and Rho/Rac GEF) are also altered. These combined altered pathways underscore the importance of the regulation of genes of the microenvironment in this disease [58]. Finally, in this model, genes of the class II PI3K family and Pten were also downregulated as observed in the HRMDS model (Tables 2, 4, and 5).

As in the HR-MDS GEP study, we analyzed the 54 genes that were differentially expressed between the AML post MDS model and its founders (i.e., upregulated in the AML post MDS and downregulated in the founders or vice versa) (Fig. 6d and Additional file 1: Table S15). These 


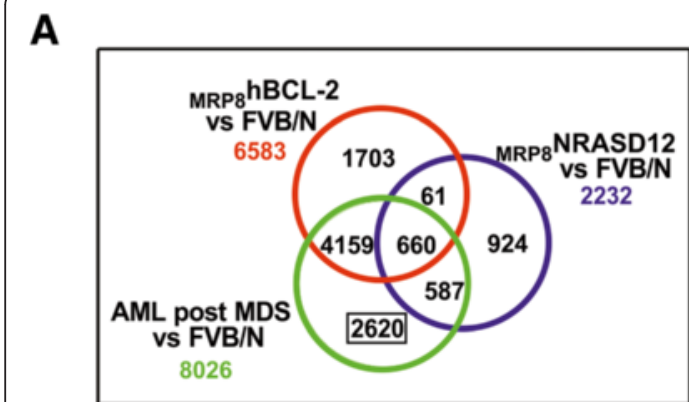

D

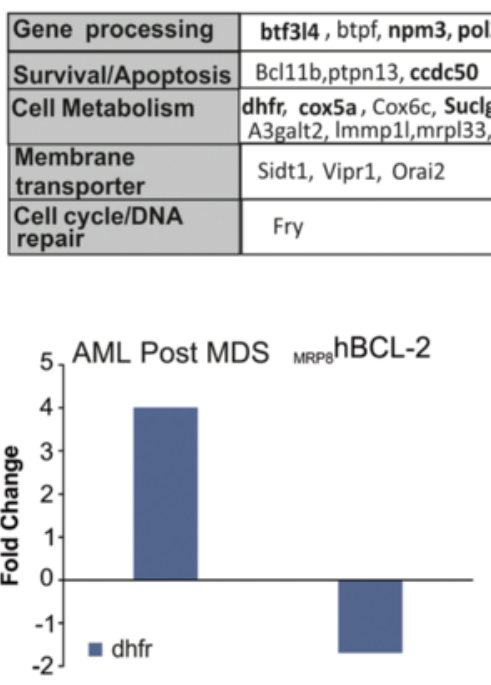

AML post MDS

B

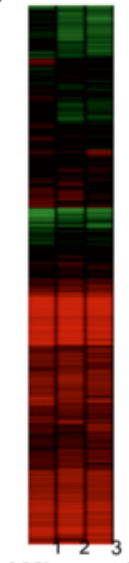

AML post MDS

vs FVB/N
C

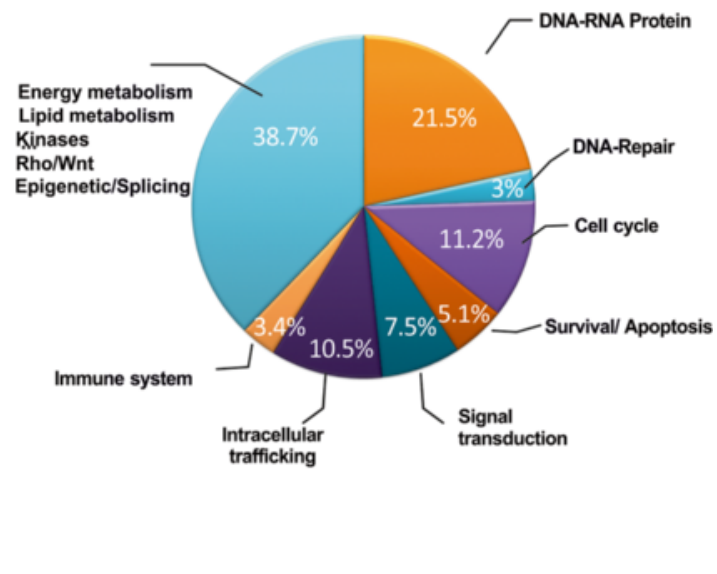

\begin{tabular}{|l|l|}
\hline $\begin{array}{l}\text { Gene processing } \\
\text { (splicing) }\end{array}$ & Hnrnpf \\
\hline Cell metabolism & Cycs \\
\hline
\end{tabular}
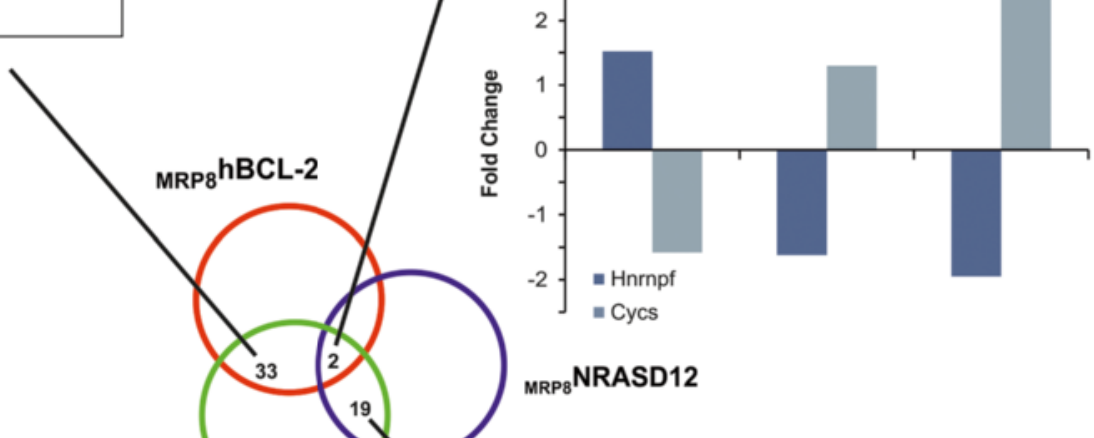

AML Post MDS

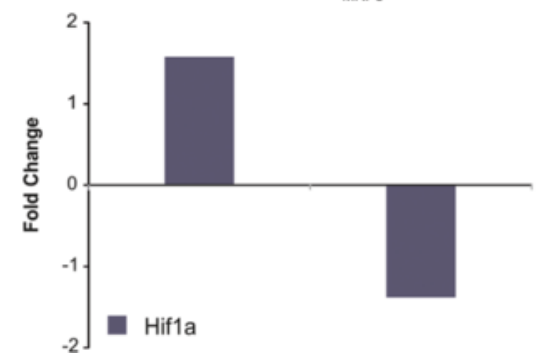

\begin{tabular}{|l|l|}
\hline Gene processing & pmf1, ncbp1, HIF1a \\
\hline Protein processing & Ufm1 \\
\hline Survival/Apoptosis & $\begin{array}{l}\text { tnfrsf18, Dnase2a, } \\
\text { ptpn13 }\end{array}$ \\
\hline Cell Metabolism & Coq4, Pdp1, Gnptg \\
\hline $\begin{array}{l}\text { Membrane } \\
\text { transporter/receptor }\end{array}$ & $\begin{array}{l}\text { Clcn5 II12rb2, M6pr-ps } \\
\text { ŠL4011(ferroportin), ccr3 } \\
\text { (CD193),CD163, ankrd55 }\end{array}$ \\
\hline Cell cycle/DNA repair & Rad18 \\
\hline
\end{tabular}

Fig. 6 a Venn diagrams of co-expressed and uniquely dysregulated genes compared to control FVB/N mice in the AML post MDS, MRP8NRASD12 and ${ }_{\text {MRPs }} \mathrm{hBCL}-2$ transgenic mice; $\mathbf{b}$ Heat Map of GEP performed on the Sca1+ cells of AML post MDS mice $(n=3)$ compared to control FVB/N mice $(n=3)$; c Distribution in \% of the significantly dysregulated genes in the KEGG DAVID annotation pathways; $\mathbf{d}$ Analysis of the differentially expressed (i.e., upregulated in the AML post MDS transgenic mice and downregulated in the founder mice and vice versa). Genes in regular font are expressed at lower levels and genes in bold font are expressed in higher levels. Examples of microarray data are shown for each intersection 
Table 4 Top regulated pathways in the list of upregulated genes in AML post MDS mice

\begin{tabular}{|c|c|c|c|}
\hline Functional pathway KEGG database & $n$ & Up $P$ Value & Upregulated genes $^{\mathrm{a}}$ \\
\hline \multirow[t]{4}{*}{$\begin{array}{l}\text { Cell metabolismOxidative } \\
\text { phosphorylation }\end{array}$} & \multirow[t]{4}{*}{18} & \multirow[t]{4}{*}{$1.0 \mathrm{E}-03$} & $\begin{array}{l}\text { NDUFB5, NDUFB6, NDUFB8, ATP5B, COX4I1, NDUFC1, COX5A, LHPP, NDUFA10, } \\
\text { ATP5G3, PPA2, NDUFB2, ATP6V0C, ATP6V1A, UQCR11, NDUFV1, SDHC, COX6B2 }\end{array}$ \\
\hline & & & NDUF family: NADH dehydrogenase (ubiquinone) Fe-S family \\
\hline & & & SDHC: succinate dehydrogenase complex, subunit C \\
\hline & & & LHPP: phospholysine phosphohistidine inorganic pyrophosphate phosphatase \\
\hline \multirow[t]{4}{*}{$\begin{array}{l}\text { Nucleotide metabolism Pyrimidine } \\
\text { metabolism }\end{array}$} & \multirow[t]{4}{*}{14} & \multirow[t]{4}{*}{$2.9 \mathrm{E}-03$} & $\begin{array}{l}\text { POLR2G, NUDT2, DTYMK, POLE, AK3, POLA1, POLR2C, NME4, TYMP, POLE3, NME1, } \\
\text { POLD1, ENTPD1, DUT }\end{array}$ \\
\hline & & & NUDT2: nucleoside diphosphate, AK3: adenylate kinase \\
\hline & & & TYMP: thymidine phosphorylase, NME: nucleoside diphosphate kinase \\
\hline & & & POLE, POLR2C, POLE3, PLD1: polymerases, DUT: deoxyuridine triphosphate \\
\hline \multirow[t]{3}{*}{$\begin{array}{l}\text { Immune systemToll-like receptor } \\
\text { signaling }\end{array}$} & \multirow[t]{3}{*}{14} & \multirow[t]{3}{*}{$3.8 \mathrm{E}-03$} & $\begin{array}{l}\text { MAP2K3, MAP2K4, TLR4, FADD, CXCL11, TLR7, CCL4, TLR8, CD80, IFNA7, MAPK13, } \\
\text { IFNA5, TICAM2, PIK3R2 }\end{array}$ \\
\hline & & & MAP2K3, MAP2K4: MEK proteins, TICAM2: TIR domain-containing adapter molecule 2 \\
\hline & & & PIK3R2: Phosphatidylinositol 3-kinase regulatory subunit beta \\
\hline \multirow[t]{4}{*}{ Cellular processesCell cycle } & \multirow[t]{4}{*}{16} & \multirow[t]{4}{*}{$5.8 \mathrm{E}-03$} & $\begin{array}{l}\text { CDC6, E2F3, CCNH, SKP2, YWHAB, ESPL1, CDC20, CHEK1, CHEK2, CDC25C, MCM4, } \\
\text { 2CDK2, CCNE2, CDC45, MAD2L1, CDKN2C }\end{array}$ \\
\hline & & & CCNH: cyclin H; SKP2: S-phase kinase-associated protein 2; YWHAB: 14-3-3 protein beta/alphe \\
\hline & & & ESPL1:separin, CCNE2: cyclin E2, MAD2L1: MAD2 mitotic arrest deficient-like 1 \\
\hline & & & CDKN2: cyclin-dependent kinase inhibitor 2A (p16) \\
\hline \multirow[t]{6}{*}{$\begin{array}{l}\text { Signaling molecules Cytokine- } \\
\text { cytokine receptor }\end{array}$} & \multirow[t]{6}{*}{25} & \multirow[t]{6}{*}{$5.9 \mathrm{E}-03$} & $\begin{array}{l}\text { IL1R1, ACVRL1, PDGFB, IL13, CXCL11, CCL4, TNFRSF4, IL10, IL12RB2, CCL22, IFNA7, } \\
\text { IFNA5, TNFRSF18, IFNGR1, EPO, IL4, IL23R, IL21, CCL17, TNFRSF9, INHBA, CCR8, } \\
\text { TNFSF11, CXCL13, CCR2 }\end{array}$ \\
\hline & & & IL1R1, IL12RB, I L23R,IL21: interleukines/interleukine receptor \\
\hline & & & CCL4, CCL22, CCL17, CXCL11, CXCL13 CCR2, CCR8: chemokine \\
\hline & & & TNFRSF4, TNFRSF18, TNFRSF9, TNFSF11. Tumor necrosis receptor \\
\hline & & & IFNA7, IFNA5, INFGR1, INHBA: interferon signaling \\
\hline & & & EPO: erythropoietin \\
\hline
\end{tabular}

IL4, IL23R, SOCS2, IL13, IL21, IL10, IL12RB2, SPRY1, IFNA7, IFNA5, SPRED2, IFNGR1, IL13RA2, EPO, PIK3R2

IL4, IL23R, IL13, IL21, IL10, IL12RB2, IL13RA2: interleukines/interleukine receptor

IFNA7, IFNA5, IFNGR1: interferon signaling

EPO: erythropoietin

PIK3R2: phosphoinositide-3-kinase, regulatory subunit 2

Genetic information processing. Replication and repair

Genetic information processing
$5 \quad 6.4 \mathrm{E}-02$

BLM, RAD51L1, POLD1, RAD54B, RAD51

BLM: bloom syndrome protein, POLD1: polymerase delta

RAD51L1, RAD54B, RAD51: recombinases family

HIST1H2AC, C4A, H2AFV, CD80, HIST2H2BE, HIST2H2AC, HIST1H2BH, HIST1H2AI, SNRPB, H2AFY, FCGR1, IL10

HIST1H2AC,H2AFV,HIST2H2BE,HIST2H2AC,HIST1H2BH, HIST1H2Al, H2AFY: histone proteins

C4A: complement factor 4; CD80, costimulatory factor, SNRPB: small nuclear ribonucleoprotein-associated proteins B, FCGR1: IgG FC receptor

${ }^{\mathrm{a} G e n e}$ card nomenclature

genes predominated in the functional pathway gene processing (DNA-RNA-protein) such as pmf1, btf3l4, bptf, npm3, pol2rc, ncbp1, Ufm1, hnrnpf, and Hif1a. Several of these genes are implicated in leukemogenesis such as the npm genes (nmp1 and nmp3). HIF1 $\alpha$ is a key partner of glycolysis (Fig. 3b) [59] and a target gene of E2F3
[60]. Both HIF1 $\alpha$ (Additional file 1: Table S17) and E2F3 (Additional file 1: Table S16) genes are upregulated in the AML post MDS. MDS patients have been reported to express high levels of E2F3 and $d h f r$ [61] and Hif1 $\alpha$ [62] underscoring the relevance of the mice model. Genes of cellular processes such as survival/ 
Table 5 Top regulated pathways in the list of downregulated genes in AML post MDS mice

\begin{tabular}{|c|c|c|c|}
\hline Functional pathway KEGG database & $\mathrm{n}$ & Down $P$ value & Downregulated genes ${ }^{a}$ \\
\hline \multirow[t]{2}{*}{ Cellular processes Inhibition of Apoptosis } & \multirow[t]{2}{*}{5} & \multirow[t]{2}{*}{$1.2 \mathrm{E}-2$} & NAIP6, NAIP5, NLRC4, MAPK9, TNFAIP3 \\
\hline & & & $\begin{array}{l}\text { NAIP6; NAIP5: NLR family, apoptosis inhibitory protein 6; NLRC4: NLR family CARD } \\
\text { domain-containing protein 4; MAPK9: mitogen activated kinase 9; TNFAIP3: tumor } \\
\text { necrosis factor, alpha-induced protein } 3\end{array}$ \\
\hline \multirow[t]{4}{*}{ Environmental adaptation Circadian rhythm } & \multirow[t]{4}{*}{3} & \multirow[t]{4}{*}{$1.4 \mathrm{E}-2$} & NR1D1, PER1, CLOCK \\
\hline & & & NR1D1: nuclear receptor subfamily 1, group D, member 1 \\
\hline & & & PER1: period circadian clock 1 \\
\hline & & & CLOCK: circadian locomotor output cycles kaput \\
\hline \multirow{5}{*}{$\begin{array}{l}\text { Signal transduction Phosphatidylinositol } \\
\text { signaling system }\end{array}$} & \multirow[t]{5}{*}{5} & \multirow[t]{5}{*}{$2.2 \mathrm{E}-2$} & PIK3C2A, PIK3C2B, PIP4K2A, PTEN, ITPR1 \\
\hline & & & PIK3C2A: phosphatidylinositol-4-phosphate 3-kinase \\
\hline & & & PIP4K2A: phosphatidylinositol-5-phosphate 4-kinase, type II, \\
\hline & & & PTEN: phosphatase and tensin homolog \\
\hline & & & ITPR1: Inositol 1,4,5-trisphosphate receptor type 1 \\
\hline \multirow[t]{4}{*}{ Human diseasesType II diabetes mellitus } & \multirow[t]{4}{*}{4} & \multirow[t]{4}{*}{$3.2 \mathrm{E}-2$} & IRS2, MAPK9, CACNA1E, SOCS4 \\
\hline & & & IRS2: insulin receptor substrate 2; MAPK9: mitogen activated kinase 9 \\
\hline & & & CACNA1E: calcium channel, voltage-dependent, $R$ type, alpha $1 E$ subunit \\
\hline & & & SOCS4: suppressor of cytokine signaling 4 \\
\hline \multirow[t]{2}{*}{ Human diseasesPrimary immunodeficiency } & \multirow[t]{2}{*}{3} & \multirow[t]{2}{*}{$9.3 \mathrm{E}-2$} & CD19, RFX5, CD40 \\
\hline & & & $\begin{array}{l}\text { CD19: antigen receptor of B lymphocytes; RFX5: regulatory factor X; } \\
\text { CD40: TNF receptor superfamily member } 5\end{array}$ \\
\hline
\end{tabular}

apoptosis, cell cycle, and DNA repair were also differentially expressed. Genes of cell metabolism were also identified such as genes coding for succinate-CoaA ligase, cytochrome c oxidase (Coxa5, Cox6), Coq4, or dihydrofolate reductase $(d h f r)$. Two genes (cysc and hnrnpf) were dysregulated between the AML post MDS mice and both founder. The Hnrnpf gene (heterogeneous nuclear ribonucleoprotein F) is involved in the regulation of alternative splicing [63] and has been found altered in myeloid malignancies [63] while the cysc gene codes for cytochrome $\mathrm{C}$ in the electron respiratory chain and is also a major mitochondrial initiator of the apoptosis intrinsic pathway (Fig. 3b). Finally, other dysregulated genes involved membrane transporter genes (such as iron (Slc40a1/ferroportin), calcium (Orai2), $\mathrm{H}+/ \mathrm{Cl}-(\ln c 5)$, small RNAs (Sidt1), ankyrine (ankrd55) or membrane receptor genes (vasopressine (Vipr1), scavenger (CD163), mannose phosphate (M6pr-ps), chemokine (ccr3), and IL12 (IL12tb2). Of note, the role of the iron transporter was reported in MDS [64].

\section{Validation of GEP}

The GEP microarray data was validated on a different set of HR-MDS mice produced a year after the mRNA extraction for the GEP analysis on both BM and spleen Sca1+ purified cells. A similar dysregulation of gene expression was noted on three selected pathways, angpt1 (signal transduction), cox4i1 and ndufv2 (oxidative metabolism), and $s d c 1$ (DNA processing). For all these genes, there was a concordance between (a) the array analysis and the RT-PCR study and (b) a concordance between the spleen and bone marrow gene expression validating the study performed on spleen cells (Fig. 4). We also confirmed the decreased expression of one of these MAPK, MAP2K, at the protein level in another set of AML post MDS mice cells by nanofluidic proteomic immunoassay (Fig. 5e).

The relevance of the GEP results was also validated in CD34+ BM cells of MDS patients $(n=3)$ on the same gene panel. For these pathways (signal transduction, oxidative metabolism, and DNA processing), the dysregulation was the same in the BM of HR-MDS mice and MDS patient CD34+ BM cells when compared to normal FVB/N control cells and normal CD34 BM cells (Fig. 4). This is the only discrepancy we noted when comparing the HRMDS mice GEP data with gene expression data in MDS patient samples (whether from data of the literature or validation analysis performed in this study). However, the complete disruption noted in the MDS patient samples is in line with that reported in patients with solid tumors $[65,66]$ and strengthens their potential relevance to human MDS though how these pathways impact on the disease still needs to be elucidated as in solid tumors.

Thus, the GEP analysis of these mice, at the gene expression level, validates them as unique models of human MDS, at two different stages of the human MDS disease, 
Table 6 Genes implicated in WNT signaling differentially dysregulated in the AML post MDS transgenic mice compared to control $\mathrm{FVB} / \mathrm{N}$ mice

\begin{tabular}{|c|c|c|c|c|}
\hline Gene symbol & Gene name & Regulation & Fold change & $P$ value \\
\hline Mesdc2 & Mesoderm development candidate 2 & Up & 1.98 & $1.92 \mathrm{E}-02$ \\
\hline Csnk2b & Casein kinase 2 , beta polypeptide & Up & 1.88 & $1.76 \mathrm{E}-02$ \\
\hline Fzd7 & Frizzled homolog 7 & Up & 1.75 & 2.74E-03 \\
\hline Ctnnb1 & Catenin (cadherin associated protein), beta 1 & Up & 1.74 & 4.24E-04 \\
\hline Bambi & BMP and activin membrane-bound inhibitor, homolog (Xenopus laevis) & Up & 1.73 & $1.56 \mathrm{E}-02$ \\
\hline Dab2 & Disabled homolog 2 & Up & 6.67 & 2.12E-02 \\
\hline $\mathrm{Cd} 44$ & CD44 antigen & Up & 1.68 & $5.96 \mathrm{E}-03$ \\
\hline Wdr61 & WD repeat domain 61 & Up & 1.64 & 7.57E-04 \\
\hline Sdc1 & Syndecan 1 & Up & 3.11 & 5.94E-03 \\
\hline Hhex & Hematopoietically expressed homeobox & Down & 1.98 & 2.46E-02 \\
\hline Macf1 & Microtubule-actin crosslinking factor 1 & Down & 1.94 & $8.80 \mathrm{E}-03$ \\
\hline Mark2 & MAP/microtubule affinity-regulating kinase 2 & Down & 1.94 & 2.41E-02 \\
\hline Tnik & TRAF2 and NCK interacting kinase & Down & 1.91 & $3.10 \mathrm{E}-03$ \\
\hline Tle1 & Transducin-like enhancer of split 1, homolog of Drosophila E(spl) & Down & 1.88 & $1.51 \mathrm{E}-02$ \\
\hline Dvl2 & Dishevelled 2, dsh homolog (Drosophila) & Down & 1.67 & 7.34E-03 \\
\hline Csnk1a1 & Casein kinase 1, alpha 1 & Down & 1.65 & 1.27E-02 \\
\hline Rock1 & Rho-associated coiled-coil containing protein kinase 1 & Down & 1.61 & 7.04E-03 \\
\hline Map3k7 & Mitogen-activated protein kinase kinase kinase 7 & Down & 1.58 & 9.96E-04 \\
\hline Smad4 & MAD homolog 4 & Down & 1.54 & $6.36 \mathrm{E}-03$ \\
\hline Dapk3 & Death-associated protein kinase 3 & Down & 1.52 & 1.06E-02 \\
\hline Tbl1xr1 & Transducin (beta)-like 1X-linked receptor 1 & Down & 1.52 & 8.39E-04 \\
\hline Рpp3ca & Protein phosphatase 3, catalytic subunit, alpha isoform & Down & 1.50 & 9.70E-03 \\
\hline Ppap2b & Phosphatidic acid phosphatase type $2 \mathrm{~B}$ & Down & 2.10 & 2.74E-02 \\
\hline
\end{tabular}

high risk (HR-MDS), and at transformation (AML post MDS). Though published MDS mice models have provided insights to initiating mechanisms such as splicing abnormalities, chromosomal deletions, or abnormalities of the microenvironment [25,67], most are characterized by myeloid proliferation, whether chronic or acute, with little reported analysis of apoptosis, and very few have achieved a translational benefit.

The majority of the identified pathways in the HR-MDS and AML post MDS mice identified by this GEP analysis are similar to those reported in similar annotation studies performed in MDS patients, when all analyses are combined [11-14, 16, 18-22, 24, 43, 45, 56-58, 64, 68-77]. Most of the dysregulated pathways were expected in a malignant context, such as pathways of gene processing, intracellular trafficking, cell cycle, DNA damage-repair, signal transduction, the immune system, and oxidative metabolism (Fig. 7a), and confirmed by GSEA analysis performed on all genes dysregulated in HR-MDS (Additional file 1: Table S29, Additional file 2: Figure S1A) or AML post MDS (Additional file 1: Table S30, Additional file 2: Figure $\mathrm{S} 1 \mathrm{~B}$ ) vs $\mathrm{FVB} / \mathrm{N}$ mice. The latter three annotation pathways are more frequently dysregulated in the AML post MDS mice. A more focused analysis on pathways now known to be implicated in MDS and AML [3, 18] also identified dysregulation of genes coding for epigenetic proteins (Additional file 1: Table S13 and S27), enzymes involved in methylation and acetylation processes (Additional file 1: Tables S4, S18 and Additional file 3: Figure S2D) as well as genes implicated in splicing and translation in both diseases (Additional file 1: Tables S4, S16, S18), confirming the importance of altered epigenetic, splicing, or ribosomal pathways in MDS diseases whether they are induced by mutations or altered gene expression. Thus, both mice models may be useful to further analyze and target these known pathways.

The GEP and annotation analysis equally identified novel dysregulated pathways, most of which have been identified in the solid tumor field but not as yet in AML or MDS. These pathways, detailed above, concern lipid and ether metabolism, the proteasome, MAPKinases, and more specifically, the noncanonical Wnt (Fig. 7b). The dysregulation of these pathways was confirmed by the differential gene expression (or nanofluidic proteomic immunoassay) seen in the BM and spleen cells of a different set of MDS mice and in the BM CD34+ cells of 


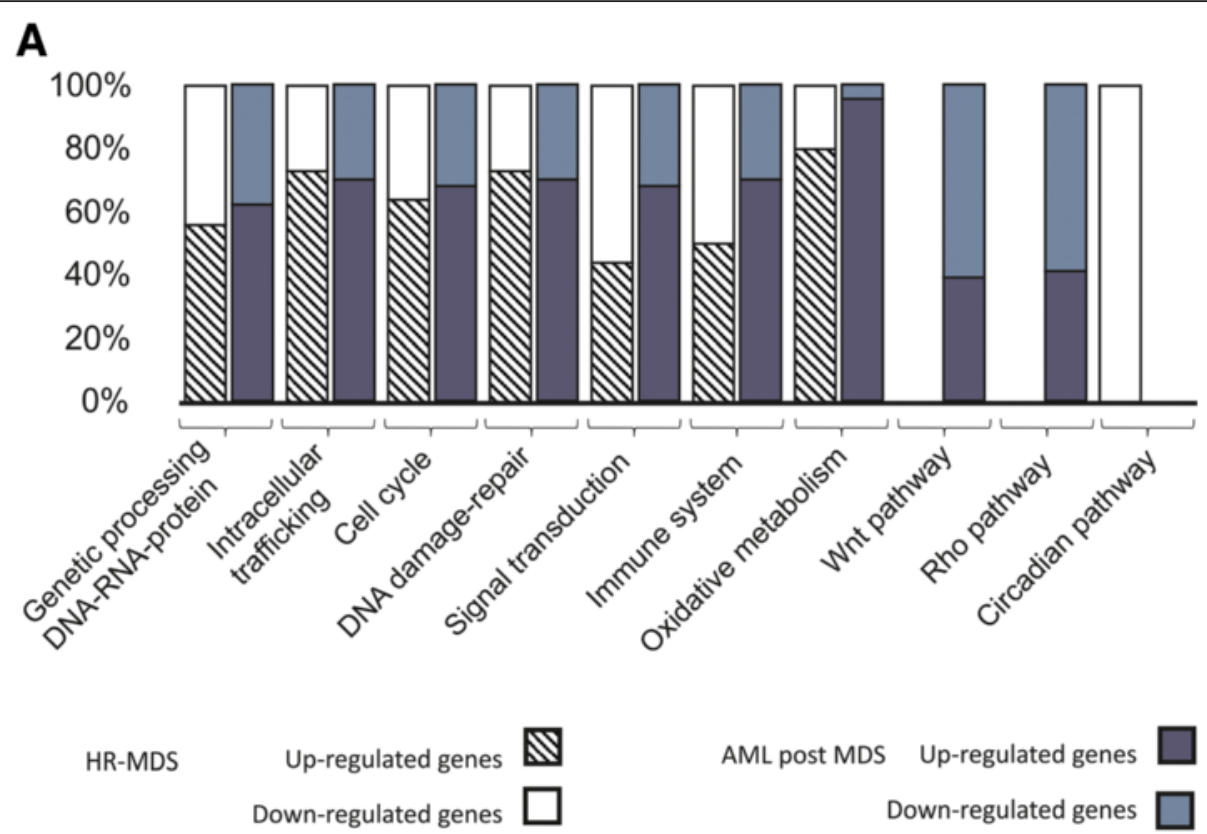

B

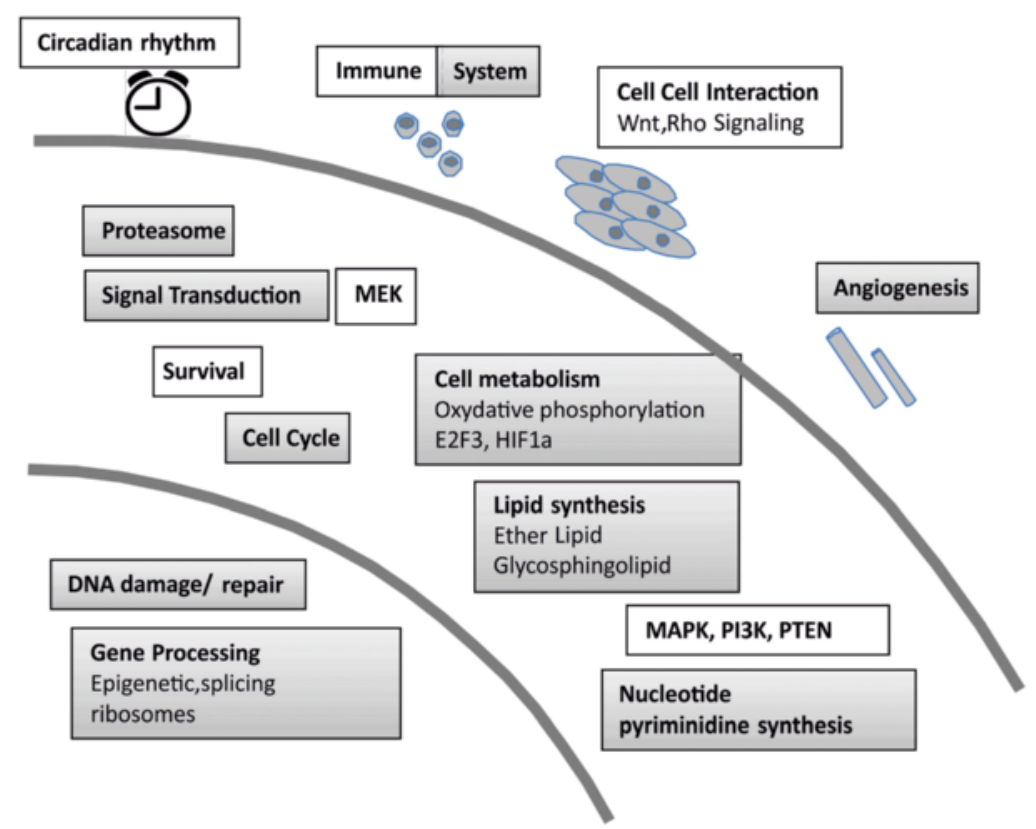

Fig. 7 a Frequency in percent of the most significant pathways dysregulated (up- or downregulated) in the two MDS mice models; b Schematic summary of the dysregulated pathways noted in the two MDS mice models. Upregulated pathways (gray boxes), downregulated pathways (white boxes)

MDS patients when compared to their normal counterparts (Figs. 2e, 4). How these dysregulations occur and impact on the initiation or maintenance of MDS and in the networks of the other dysregulated pathways will require further studies.

\section{Conclusions}

In conclusion, this study confirms that the HR-MDS and AML post MDS mice mimic two stages of the human
MDS disease not only in their clinical and biological level but also in their gene expression level. This study further highlights novel less well studied pathways such as energy and lipid metabolism and noncanonical Wnt signaling which may concur with epigenetics and DNA damage to the genomic instability of these diseases. These MDS models should help unravel the underlying networks at the origin of these dysregulation and provide further biomarkers and targets for MDS disease. 


\section{Methods}

\section{Transgenic mice}

The MRP8[NRASD12/hBCL-2] (AML post MDS) and MRP8NRASD12/ tethBCL-2 (HR-MDS) transgenic mice were generated from crosses of MRPshBCL-2 or MMTVLTRtTA/

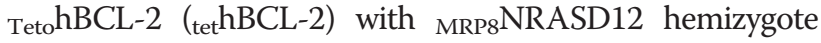
mice in $\mathrm{FVB} / \mathrm{N}$, as previously described [33, 34]. For genotyping, DNA was extracted from the tails of 3-week-old mice using the KAPA Express Extraction Kit using manufacturer instructions. The PCR reaction was then performed with $\mathrm{REDTaq}^{\circ}$ ReadyMixTM PCR Reaction Mix with $\mathrm{MgCl} 2$. Mice were classified according to the Bethesda classification [78] as HR-MDS or AML post MDS-like by cytological and pathology criteria. Mice were maintained in the barrier facilities of the Institut Universitaire d'Hématologie. Procedures involving animals and their care conformed with institutional guidelines that comply with national and international laws and policies and were authorized by the local ethical committee. Mice were sacrificed when they were moribund or upon veterinary advise. Committee on the Ethics of Animal Experiments Paris-Nord: C2EA-121 approved this project no. 2014IUH006

\section{Cell and tissue preparation, flow cytometry}

The bone marrow (BM) was obtained by flushing long bones with Hank's balanced salts solution followed by filtering through a nylon mesh. BM smears were prepared according to standard hematological techniques. BM smears were stained and examined by a cytologist (MEN) of Hôpital Saint-Louis. Percentage blasts were determined from the BM smears by counting 100-200 cells. Spleen cells from AML post MDS mice (day 36 post birth) and HR-MDS mice (day 80 post birth) were obtained by soft dilaceration of the spleen with the piston of a $5-\mathrm{ml}$ syringe in a petri dish. Cells were washed in PBS, filtered through a $40-\mu \mathrm{m}$ nylon mesh and then density centrifugation was conducted using Lymphoprep (Eurobio, France) to isolate mononuclear cells. Spleen or BM cells were labeled with anti-Sca1+ antibodies coupled with microbeads from Miltenyi and then sorted using an AutoMacs separator (Miltenyi Biotec Bergisch Gladbach, Germany). $5 \cdot 10^{6}$ to $10^{7} \mathrm{Sca} 1+$ sorted cells were used to extract total RNA using TRIzol (Invitrogen, CA, USA). Quantification and quality of the RNAs were assessed using a Nanodrop (Thermoscientific, USA).

Secondary transplantation of bone marrow and spleen cells Bone marrow cells, isolated from long bones, and spleen cells were harvested from 6- to 10-week-old AML post MDS mice as described above, pooled and divided $\left(10^{7}\right.$ nucleated cell aliquots per recipient) for i.v. injections into 12 irradiated FVB/N mice. Six- to 8-week-old FVB/ $\mathrm{N}$ mice were prepared for transplantation by cesium irradiation totaling $10 \mathrm{~Gy}$, divided into two doses 3 to $4 \mathrm{~h}$ apart. Successful transfer of the transgene-positive cells was confirmed by PCR. Spleen cells $\left(10^{5}, 10^{6}\right.$, or $10^{7}$ ) from HR-MDS mice were injected i.v. in tail veins of immunocompromised RAG1-deficient mice, which are $B$ cell and $T$ cell deficient. [79]

\section{Nanofluidic proteomic immunoassay (NanoPro assay)}

Splenocyte cells $\left(10^{6}\right)$ isolated from transgenic mice were lysed in radio immunoprecipitation assay buffer and subjected to a nanofluidic proteomic immunoassay (NIA) run on the NanoPro1000, as we have previously described [80] (ProteinSimple, Santa Clara, CA) mixing $0.1 \mathrm{mg} / \mathrm{mL}$ of lysate in a final volume of $15 \mu \mathrm{L}$ loaded in a 384-well plate with five to eight gradient ampholyte mix. Antibodies were diluted in ProteinSimple antibody diluent: mitogenactivated protein kinase (MEK)1 (Upstate 07-641; Millipore, Billerica, MA) 1:100. Samples were run in triplicate.

\section{${ }^{99}$ Tc-Annexin scintigraphy}

Single-Photon Emission Computed Tomography (SPECT) was performed under pentobarbital anesthesia $(4 \mathrm{mg} /$ 100 g body weight; Ceva Santé Animale, Libourne, France) in mice, after intravenous injection of ${ }^{99} \mathrm{Tc}$-Annexin. Images were acquired $10 \mathrm{~min}$ after injected dose of ${ }^{99} \mathrm{Tc}$-Annexin. Planar images were obtained 0 to $45 \mathrm{~min}$ (dynamic acquisition: 15 images, image duration: $60 \mathrm{~s}$, static acquisitions of $10 \mathrm{~min}$ duration) after ${ }^{99} \mathrm{Tc}$-Annexin injection. In addition, mice which had previously undergone planar imaging underwent abdominal X/tomoscintigraphy acquisition: mod-list tomographic acquisition was performed during continuous rotation of the animal placed between two parallel collimators $\left(360^{\circ}\right.$ rotation per minute, acquisition duration: $60 \mathrm{~min}$ from $1 \mathrm{~h}$ to $2 \mathrm{~h}$ after ${ }^{99} \mathrm{Tc}$-Annexin injection). All acquisitions were performed using a dedicated small animal IMAGER-S/CT system (Biospace Mesures, Paris, France) equipped with parallel low-energy high-resolution collimators (matrix $128 \times 128,15 \%$ energy window centered on $140 \mathrm{KeV}) .{ }^{99} \mathrm{Tc}$-Annexin uptake in hepato-splenic area was visually assessed.

\section{Affymetrix exon array hybridization}

One microgram of total RNA extracted from Sca1+ spleen cells from the AML post MDS mice, HR-MDS mice, singletransgenic mice necessary to produce these AML post MDS and HR-MDS mice, (MRP8 NRASD12, ${ }_{\text {MRP }}$ hBCL-2, tet $\mathrm{hBCL}-2$ ) (called founder mice), and FBV/N control mice ( $n=3$ each) was labeled with Affymetrix reagents and hybridized to Affymetrix-GeneChip Mouse Exon 1.0 ST arrays. Affymetrix Expression Console Software was used to perform quality assessment.

For each of the 18 arrays (MRP8NRASD12/ ${ }_{\text {tet }} \mathrm{hBCL}-2$, MRP8 [NRASD12/hBCL-2], MRP8NRASD12, MRP8hBCL-2, 
tet $\mathrm{hBCL}-2$, and the control FVB/N mice), 100 ng of total RNA was first mixed with bacterial transcripts and the mixture was reverse transcribed into complementary DNA (cDNA). After synthesis of double-stranded cDNA, an in vitro transcription reaction was conducted overnight. Resulting amplified cRNA was reverse transcribed into sense DNA incorporating dUTP. This single-stranded DNA was treated with a combination of uracil DNA glycosylase and apurinic/apyrimidinic endonuclease 1. DNA fragments were biotin-labeled by terminal deoxynucleotidyl transferase. Targets were finally prepared according to Affymetrix recommendations for hybridization of exon arrays. Microarrays were hybridized, washed, and scanned using Affymetrix instruments. Total RNAs RIN values were between 8.3 and 9. Raw data are controlled with Expression console (Affymetrix).

\section{Microarray data and statistical analysis}

Affymetrix exon array data analyses were performed using EASANA based on FAST DB annotations [81] (GenoSplice technology; http://www.genosplice.com/). Unpaired statistical analyses were performed using Student's paired $t$ test as previously described [82]. Affymetrix Expression Console Software was used to perform quality assessment. All array present a "pos_vs_neg_auc" value greater or equal than 0.82; All arrays present a "all_probeset_rle_mean" value lesser or equal than 0.35; All arrays present a "\%" value greater or equal than $65 \%$ and less than $6 \%$ of difference between arrays from the same experimental condition.

Regarding the expression status/background noise analysis, only probes with a DABG $P$ value $\leq 0.05$ in at least half of the arrays from a given experimental condition were considered for further statistical analysis.

We kept a cutoff of $P$ value $\leq 0.05$ of increase or decrease of expression compared to normal samples for the analysis [83], Gene Set Enrichment Analysis (GSEA), and gene ontology using the Database for Annotation, Visualization and Integrated Discovery (DAVID) (http:// https://david.abcc.ncifcrf.gov) were performed [84-87]. Though our analysis is focused on the unique genes dysregulated in the HR-MDS and the AML post MDS transgenic mice and sets of genes differentially expressed in HR-MDS or AML post MDS and founders, the data from all mice was analyzed as of potential relevance to the initiation of the disease (Additional file 1: Tables S1-28). This resulted in a selection of 2674 genes unique for AML post MDS and 715 for HR-MDS that were used for functional analysis. Microarray data from this study were included in the NCBI Gene Expression Omnibus no. GSE72934.

\section{HR-patient samples}

BM aspirates from MDS patients were obtained in accordance with the Declaration of Helsinki. Participants provide their written informed consent to participate in Cancer research. The study presented here is part of a study approved by "Comité d'Evaluation de l'Ethique des Projets de Recherche Biomédicale" (CEERB) Paris Nord-IRB00006477-on 17 June 2013 (opinion number 13-027).

Patients had been diagnosed according to the World Health Organization (WHO) 2008 classification [88, 89]. CD34+ enriched cells were obtained by using anti-CD34+ antibodies coupled with microbeads from Miltenyi and then sorted using an AutoMacs separator (Miltenyi Biotec Bergisch Gladbach, Germany). CD34+ sorted cells were used to extract total RNA using TRIzol (Invitrogen, CA, USA).

\section{Real-time RT-PCR}

Total RNA $(1 \mu \mathrm{g})$ was reverse transcribed with SuperScript III reverse transcriptase (Invitrogen) using $100 \mathrm{ng}$ of Random Hexamers. Quantitative real-time RT-PCR was performed in a test set of HR-MDS mice $(n=3)$ Sca1+ enriched BM and spleen cells and MDS patients $(n=3)$ CD34+ enriched BM using Power SYBR ${ }^{\circ}$ Green (Applied Biosystems) and 7500 Fast Real-Time PCR System, Applied Biosystems. Primer sequences are detailed in Additional file 1: Table S31.

\section{Additional files}

Additional file 1: Lists of regulated genes in HR-MDS and AML post MDS relative to FVB/N (Tables S1 to S31). (XLSX $1839 \mathrm{~kb}$ )

Additional file 2: Figure S1. GSEA analysis, (A) Endplot of significantly dysregulated pathways in HR-MDS vs FVB/N, (B) Endplot of significantly dysregulated pathways in AML post MDS vs FVB/N (ZIP $5853 \mathrm{~kb}$ )

Additional file 3: Figure S2. In a preliminary work, mRAS-BCL2 (referred in this study as MRP8[NRASD12/ hBCL-2], AML post MDS mice) transgenic mice Sca1+ spleen cells genes were analyzed on Affimetrix 430A mouse arrays. Compared to normal FVB/N Sca1+ spleen cells, (A) DAVID analysis, (B) Principal component analysis (PCA), and hierarchical clustering, were performed with R software (http://www.R-project.org) and Partek Genomics Suite (http://www.partek.com). Each sphere represents a single GEP from a given transgenic mouse: mRas (referred in this study as MRP8NRASD12 transgenic mice), $\mathrm{mBCL} 2$ transgenic mice (referred in this study as MRP8hBCL-2 transgenic mice), mRAS-BCL2 transgenic mice (referred in this study as MRP8[NRASD12/ hBCL-2] or AML post MDS transgenic mice), (C) Gene spring single gene analysis identified significant up-regulation of ADA, KRTCAP2, SSR4, CKAP4 and ATPG3 genes in mRAS-BCL2 transgenic mice (referred in this study as MRP8[NRASD12/ hBCL-2] or AML post MDS transgenic mice). (D). In this study; ADA and KRTCAP2 were up dysregulated in MRP8hBCL2 ( $\mathrm{mBCL} 2$ ), AML post MDS (MRAS-BCL2) and HR-MDS transgenic mice Sca1+ spleen cells; SSR4 in AML post MDS (mRAS-BCL2) and HR-MDS transgenic mice Sca1+ spleen cells and; CKAP4 and ATPG3 in AML post MDS (mRAS-BCL2) transgenic mice Sca1+ spleen cells. (TIF 30355 kb)

\section{Competing interests}

P. de la Grange is a salaried employee of Genosplice. The remaining authors have no relevant conflict of interests.

Authors' contributions

$L G, S B, M S, P G$, and CLP carried out all the experiments; PdIG carried out the Affymetrix exon array and analysis; NO carried out the secondary transplant; W carried out the preparation of human CD34+ cells; LSM performed SPECT; 
MEN performed cytology and validated clinical features; KM performed the PCA analysis; GJM supervised his graduate student MS; MP was responsible for the animal facilities; PF was responsible for the recruitment of patients; FG, RAP, CC, and PK designed the experiments, analyzed the data, and wrote the manuscript. All authors read and approved the final manuscript.

\section{Acknowledgements}

This work was supported by grants from INSERM, Université Paris Diderot, Fondation de France, Association pour la Recherche Contre sur le Cancer, Association Laurette Fugain, Ligue Contre le Cancer. FP7 Marie Curie $\mathrm{N}^{\circ} \mathrm{N}^{\circ}$ 264361

\section{Author details}

${ }^{1}$ Université Paris-Diderot, Sorbonne Paris Cité, Institut Universitaire d'Hématologie, Unité Mixte de Recherche (UMR-S) 1131, Paris, France. ${ }^{2}$ Institut National de la Santé et de la Recherche Médicale (INSERM) Unité (U) 1131, Paris, France. ${ }^{3}$ Department of Haematological Medicine, King's College London and Kings College Hospital, London, UK. ${ }^{4}$ GenoSplice technology, iPEPS-ICM, Hôpital de la Pitié Salpêtrière, Paris, France. ${ }^{5}$ Haematology Department, Cardiff University School of Medicine, Cardiff, UK. ${ }^{6}$ Assistance Publique-Hôpitaux de Paris (AP-HP), Unité de Thérapie Cellulaire, Hôpital Saint Louis, Paris, France. ${ }^{7}$ Centre for Cancer Research and Cell Biology, Queen's University Belfast, Belfast, UK. ${ }^{8}$ Université Paris-Diderot, Sorbonne Paris Cité, Institut Universitaire d'Hématologie Hôpital Saint Louis, Paris, France. ${ }^{9}$ Assistance Publique-Hôpitaux de Paris (AP-HP), Service de Médecine Nucléaire, Hôpital Lariboisière, Paris, France. ${ }^{10}$ Assistance Publique-Hôpitaux de Paris (AP-HP), Laboratoire d'Hématologie, Hôpital Saint Louis, Paris, France. ${ }^{11}$ Université Paris-Diderot, Sorbonne Paris Cité, Département d'Expérimentation Animale, Institut Universitaire d'Hématologie, Paris, France.

\section{Received: 24 October 2015 Accepted: 19 January 2016}

\section{Published online: 27 January 2016}

\section{References}

1. Mughal TI, Cross NC, Padron E, Tiu RV, Savona M, Malcovati L, et al. An International MDS/MPN Working Group's perspective and recommendations on molecular pathogenesis, diagnosis and clinical characterization of myelodysplastic/myeloproliferative neoplasms. Haematologica. 2015;100(9):1117-30.

2. Fenaux P, Ades L. How we treat lower-risk myelodysplastic syndromes. Blood. 2013;121(21):4280-6.

3. Cazzola M, Della Porta MG, Malcovati L. The genetic basis of myelodysplasia and its clinical relevance. Blood. 2013;122(25):4021-34.

4. Haferlach T, Nagata Y, Grossmann V, Okuno Y, Bacher U, Nagae G, et al. Landscape of genetic lesions in 944 patients with myelodysplastic syndromes. Leukemia. 2014;28(2):241-7.

5. Hajkova H, Fritz MH, Haskovec C, Schwarz J, Salek C, Markova J, et al. CBFB-MYH11 hypomethylation signature and PBX3 differential methylation revealed by targeted bisulfite sequencing in patients with acute myeloid leukemia. J Hematol Oncol. 2014;7:66.

6. Malcovati L, Papaemmanuil E, Ambaglio I, Elena C, Galli A, Della Porta MG, et al. Driver somatic mutations identify distinct disease entities within myeloid neoplasms with myelodysplasia. Blood. 2014;124(9):1513-21.

7. Ok CY, Patel KP, Garcia-Manero G, Routbort MJ, Peng J, Tang G, et al. TP53 mutation characteristics in therapy-related myelodysplastic syndromes and acute myeloid leukemia is similar to de novo diseases. J Hematol Oncol. 2015;8:45.

8. Papaemmanuil E, Gerstung M, Malcovati L, Tauro S, Gundem G, Van LP, et al. Clinical and biological implications of driver mutations in myelodysplastic syndromes. Blood. 2013;122(22):3616-27.

9. Skvarova KK, Fiser K, Mejstrikova E, Rejlova K, Zaliova M, Fornerod M, et al. Homeobox gene expression in acute myeloid leukemia is linked to typical underlying molecular aberrations. J Hematol Oncol. 2014;7:94.

10. Visconte V, Tabarroki A, Zhang L, Parker Y, Hasrouni E, Mahfouz R, et al. Splicing factor $3 b$ subunit 1 (Sf3b1) haploinsufficient mice display features of low risk Myelodysplastic syndromes with ring sideroblasts. J Hematol Oncol. 2014;7:89.

11. Wang H, Wen J, Chang CC, Zhou X. Discovering transcription and splicing networks in myelodysplastic syndromes. PLoS One. 2013;8(11):e79118.

12. Chen G, Zeng W, Miyazato A, Billings E, Maciejewski JP, Kajigaya S, et al. Distinctive gene expression profiles of CD34 cells from patients with myelodysplastic syndrome characterized by specific chromosomal abnormalities. Blood. 2004;104(13):4210-8.

13. Del Rey M, O'Hagan K, Dellett M, Aibar S, Colyer HA, Alonso ME, et al. Genome-wide profiling of methylation identifies novel targets with aberrant hypermethylation and reduced expression in low-risk myelodysplastic syndromes. Leukemia. 2013;27(3):610-8.

14. Dellett M, O'Hagan KA, Colyer HA, Mills KI. Identification of gene networks associated with acute myeloid leukemia by comparative molecular methylation and expression profiling. Biomark Cancer. 2010;2:43-55.

15. Dolatshad H, Pellagatti A, Fernandez-Mercado M, Yip BH, Malcovati L, Attwood M, et al. Disruption of SF3B1 results in deregulated expression and splicing of key genes and pathways in myelodysplastic syndrome hematopoietic stem and progenitor cells. Leukemia. 2015;29(5):1092-103.

16. Galili N, Raza A. Clinical implications of gene expression profiling in myelodysplastic syndromes: recognition of ribosomal and translational gene dysregulation and development of predictive assays. Best Pract Res Clin Haematol. 2009;22(2):223-37.

17. Gerstung M, Pellagatti A, Malcovati L, Giagounidis A, Porta MG, Jadersten M, et al. Combining gene mutation with gene expression data improves outcome prediction in myelodysplastic syndromes. Nat Commun. 2015;6:5901.

18. Hofmann WK, de Vos S, Komor M, Hoelzer D, Wachsman W, Koeffler HP. Characterization of gene expression of CD34+ cells from normal and myelodysplastic bone marrow. Blood. 2002;100(10):3553-60.

19. Li L, Li M, Sun C, Francisco L, Chakraborty S, Sabado M, et al. Altered hematopoietic cell gene expression precedes development of therapy-related myelodysplasia/acute myeloid leukemia and identifies patients at risk. Cancer Cell. 2011;20(5):591-605.

20. Pellagatti A, Cazzola M, Giagounidis A, Perry J, Malcovati L, Della Porta MG, et al. Deregulated gene expression pathways in myelodysplastic syndrome hematopoietic stem cells. Leukemia. 2010;24(4):756-64.

21. Pellagatti A, Benner A, Mills Kl, Cazzola M, Giagounidis A, Perry J, et al. Identification of gene expression-based prognostic markers in the hematopoietic stem cells of patients with myelodysplastic syndromes. J Clin Oncol. 2013;31(28):3557-64.

22. Sridhar K, Ross DT, Tibshirani R, Butte AJ, Greenberg PL. Relationship of differential gene expression profiles in CD34+ myelodysplastic syndrome marrow cells to disease subtype and progression. Blood. 2009;114(23):4847-58.

23. Taskesen $E$, Havermans M, van Lom $K$, Sanders MA, van Norden $Y$, Bindels $E$, et al. Two splice-factor mutant leukemia subgroups uncovered at the boundaries of MDS and AML using combined gene expression and DNAmethylation profiling. Blood. 2014;123(21):3327-35.

24. Theilgaard-Monch K, Boultwood J, Ferrari S, Giannopoulos K, Hernandez-Rivas JM, Kohlmann A, et al. Gene expression profiling in MDS and AML: potential and future avenues. Leukemia. 2011;25(6):909-20.

25. Beurlet S, Chomienne C, Padua RA. Engineering mouse models with myelodysplastic syndrome human candidate genes; how relevant are they? Haematologica. 2013;98(1):10-22.

26. Chau D, Ng K, Chan TS, Cheng YY, Fong B, Tam S, et al. Azacytidine sensitizes acute myeloid leukemia cells to arsenic trioxide by up-regulating the arsenic transporter aquaglyceroporin 9. J Hematol Oncol. 2015;8:46.

27. Zhou T, Kinney MC, Scott LM, Zinkel SS, Rebel VI. Revisiting the case for genetically engineered mouse models in human myelodysplastic syndrome research. Blood. 2015;126(9):1057-68.

28. Raaijmakers MH, Mukherjee S, Guo S, Zhang S, Kobayashi T, Schoonmaker JA, et al. Bone progenitor dysfunction induces myelodysplasia and secondary leukaemia. Nature. 2010;464(7290):852-7.

29. Beurlet S, Omidvar N, Gorombei P, Krief P, Le Pogam C, Setterblad N, et al, $B C L-2$ inhibition with ABT-737 prolongs survival in an NRAS/BCL-2 mouse model of AML by targeting primitive LSK and progenitor cells. Blood. 2013;122(16):2864-76.

30. Le Pogam C, Krief P, Beurlet S, Soulie A, Balitrand N, Cassinat B, et al. Localization of the NRAS:BCL-2 complex determines anti-apoptotic features associated with progressive disease in myelodysplastic syndromes. Leuk Res. 2013;37(3):312-9.

31. Le Pogam C, Patel S, Gorombei P, Guerenne L, Krief P, Omidvar N, et al. DNA-mediated adjuvant immunotherapy extends survival in two different mouse models of myeloid malignancies. Oncotarget. 2015; 6(32):32494-508.

32. Omidvar N, Kogan S, Beurlet S, Le Pogam C, Janin A, West R, et al. BCL-2 and mutant NRAS interact physically and functionally in a mouse model of progressive myelodysplasia. Cancer Res. 2007;67(24):11657-67. 
33. Padua RA, Guinn BA, Al-Sabah Al, Smith M, Taylor C, Pettersson T, et al. RAS, FMS and p53 mutations and poor clinical outcome in myelodysplasias: a 10-year follow-up. Leukemia. 1998;12(6):887-92.

34. Parker JE, Mufti GJ, Rasool F, Mijovic A, Devereux S, Pagliuca A. The role of apoptosis, proliferation, and the BCl-2-related proteins in the myelodysplastic syndromes and acute myeloid leukemia secondary to MDS. Blood. 2000;96(12):3932-8

35. Rassool FV, Gaymes TJ, Omidvar N, Brady N, Beurlet S, Pla M, et al. Reactive oxygen species, DNA damage, and error-prone repair: a model for genomic instability with progression in myeloid leukemia? Cancer Res. 2007;67(18):8762-71.

36. Luo J, Solimini NL, Elledge SJ. Principles of cancer therapy: oncogene and non-oncogene addiction. Cell. 2009;136(5):823-37.

37. Terpos E, Verrou E, Banti A, Kaloutsi V, Lazaridou A, Zervas K. Bortezomib is an effective agent for MDS/MPD syndrome with $5 q$ - anomaly and thrombocytosis. Leuk Res. 2007;31(4):559-62

38. Yue $Y$, Wang $Y$, He $Y$, Yang $S$, Chen $Z$, Wang $Y$, et al. Reversal of bortezomib resistance in myelodysplastic syndrome cells by MAPK inhibitors. PLoS One. 2014;9(3):e90992.

39. Benjamin DI, Cozzo A, Ji X, Roberts LS, Louie SM, Mulvihill MM, et al. Ether lipid generating enzyme AGPS alters the balance of structural and signaling lipids to fuel cancer pathogenicity. Proc Natl Acad Sci U S A. 2013;110(37):14912-7.

40. Eisenmann KM, Dykema KJ, Matheson SF, Kent NF, DeWard AD, West RA, et al. $5 q$ - myelodysplastic syndromes: chromosome $5 q$ genes direct a tumorsuppression network sensing actin dynamics. Oncogene. 2009;28(39):3429-41.

41. Nyakern M, Tazzari PL, Finelli C, Bosi C, Follo MY, Grafone T, et al. Frequent elevation of Akt kinase phosphorylation in blood marrow and peripheral blood mononuclear cells from high-risk myelodysplastic syndrome patients. Leukemia. 2006;20(2):230-8.

42. Franco I, Gulluni F, Campa CC, Costa C, Margaria JP, Ciraolo E, et al. PI3K class II alpha controls spatially restricted endosomal Ptdlns3P and Rab11 activation to promote primary cilium function. Dev Cell. 2014;28(6):647-58.

43. Fuchs O, Provaznikova D, Kocova M, Kostecka A, Cvekova P, Neuwirtova R, et al. CEBPA polymorphisms and mutations in patients with acute myeloid leukemia, myelodysplastic syndrome, multiple myeloma and non-Hodgkin's lymphoma. Blood Cells Mol Dis. 2008;40(3):401-5.

44. Fenaux P, Giagounidis A, Selleslag D, Beyne-Rauzy O, Mufti G, Mittelman M, et al. A randomized phase 3 study of lenalidomide versus placebo in RBC transfusion-dependent patients with low-/intermediate-1-risk myelodysplastic syndromes with del5q. Blood. 2011;118(14):3765-76.

45. Raza A, Mehdi M, Mumtaz M, Ali F, Lascher S, Galili N. Combination of 5-azacytidine and thalidomide for the treatment of myelodysplastic syndromes and acute myeloid leukemia. Cancer. 2008;113(7):1596-604

46. Sood R, Makalowska I, Carpten JD, Robbins CM, Stephan DA, Connors TD, et al. The human RGL (RalGDS-like) gene: cloning, expression analysis and genomic organization. Biochim Biophys Acta. 2000;1491(1-3):285-8.

47. Schenkova K, Lutz J, Kopp M, Ramos S, Rivero F. MUF1/leucine-rich repeat containing 41 (LRRC41), a substrate of RhoBTB-dependent cullin 3 ubiquitin ligase complexes, is a predominantly nuclear dimeric protein. J Mol Biol. 2012;422(5):659-73.

48. Maeda T, Yagasaki F, Ishikawa M, Takahashi N, Bessho M. Transforming property of TEL-FGFR3 mediated through PI3-K in a T-cell lymphoma that subsequently progressed to AML. Blood. 2005;105(5):2115-23.

49. Ross DD. Modulation of drug resistance transporters as a strategy for treating myelodysplastic syndrome. Best Pract Res Clin Haematol. 2004;17(4):641-51.

50. Steimle V, Durand B, Barras E, Zufferey M, Hadam MR, Mach B, et al. A novel DNA-binding regulatory factor is mutated in primary MHC class II deficiency (bare lymphocyte syndrome). Genes Dev. 1995;9(9):1021-32.

51. Fukuda MN, Sato T, Nakayama J, Klier G, Mikami M, Aoki D, et al. Trophinin and tastin, a novel cell adhesion molecule complex with potential involvement in embryo implantation. Genes Dev. 1995;9(10):1199-210.

52. Bettermann K, Benesch M, Weis S, Haybaeck J. SUMOylation in carcinogenesis. Cancer Lett. 2012:316(2):113-25.

53. Pan CL, Baum PD, Gu M, Jorgensen EM, Clark SG, Garriga G. C. elegans AP-2 and retromer control Wnt signaling by regulating mig-14/Wntless. Dev Cell. 2008;14(1):132-9.

54. Pavlaki K, Pontikoglou CG, Demetriadou A, Batsali AK, Damianaki A, Simantirakis E, et al. Impaired proliferative potential of bone marrow mesenchymal stromal cells in patients with myelodysplastic syndromes is associated with abnormal WNT signaling pathway. Stem Cells Dev. 2014;23(14):1568-81.
55. Bar M, Stirewalt D, Pogosova-Agadjanyan E, Wagner V, Gooley T, Abbasi N, et al. Gene expression patterns in myelodyplasia underline the role of apoptosis and differentiation in disease initiation and progression. Transl Oncogenomics. 2008:3:137-49.

56. Gal H, Amariglio N, Trakhtenbrot L, Jacob-Hirsh J, Margalit O, Avigdor A, et al. Gene expression profiles of AML derived stem cells; similarity to hematopoietic stem cells. Leukemia. 2006;20(12):2147-54.

57. Jamieson CH, Weissman IL, Passegue E. Chronic versus acute myelogenous leukemia: a question of self-renewal. Cancer Cell. 2004;6(6):531-3.

58. Roversi FM, Lopes MR, Machado-Neto JA, Longhini AL, Duarte AS, Baratti MO, et al. Serine protease inhibitor kunitz-type 2 is downregulated in myelodysplastic syndromes and modulates cell-cell adhesion. Stem Cells Dev. 2014;23(10):1109-20.

59. Movafagh S, Crook S, Vo K. Regulation of hypoxia-inducible factor-1a by reactive oxygen species: new developments in an old debate. J Cell Biochem. 2015;116(5):696-703.

60. Arvanitis DA, Spandidos DA. Deregulation of the G1/S phase transition in cancer and squamous intraepithelial lesions of the uterine cervix: a case control study. Oncol Rep. 2008;20(4):751-60.

61. Saberwal G, Broderick E, Janssen I, Shetty V, Alvi S, Lisak L, et al. Involvement of cyclin D1 and E2F1 in intramedullary apoptosis in myelodysplastic syndromes. J Hematother Stem Cell Res. 2003;12(4):443-50.

62. Tong H, Hu C, Zhuang Z, Wang L, Jin J. Hypoxia-inducible factor-1alpha expression indicates poor prognosis in myelodysplastic syndromes. Leuk Lymphoma. 2012;53(12):2412-8.

63. Veraldi KL, Arhin GK, Martincic K, Chung-Ganster LH, Wilusz J, Milcarek C. hnRNP F influences binding of a 64-kilodalton subunit of cleavage stimulation factor to mRNA precursors in mouse B cells. Mol Cell Biol. 2001; 21(4):1228-38.

64. Boultwood J, Pellagatti A, Nikpour M, Pushkaran B, Fidler C, Cattan H, et al. The role of the iron transporter $A B C B 7$ in refractory anemia with ring sideroblasts. PLoS One. 2008;3(4):e1970.

65. Mazzoccoli G, De CA, Piepoli A, Vinciguerra M. The circadian clock and the hypoxic response pathway in kidney cancer. Tumour Biol. 2014;35(1):1-7.

66. Mazzoccoli G, Vinciguerra M, Papa G, Piepoli A. Circadian clock circuitry in colorectal cancer. World J Gastroenterol. 2014;20(15):4197-207.

67. Maegawa S, Gough SM, Watanabe-Okochi N, Lu Y, Zhang N, Castoro RJ, et al. Age-related epigenetic drift in the pathogenesis of MDS and AML. Genome Res. 2014:24(4):580-91.

68. Baratti MO, Moreira YB, Traina F, Costa FF, Verjovski-Almeida S, Olalla-Saad ST, et al. Identification of protein-coding and non-coding RNA expression profiles in CD34+ and in stromal cells in refractory anemia with ringed sideroblasts. BMC Med Genomics 2010;3:30.

69. Bhatia R, Deeg HJ. Treatment-related myelodysplastic syndrome: molecular characteristics and therapy. Curr Opin Hematol. 2011;18(2):77-82.

70. Chapuis N, Tamburini J, Cornillet-Lefebvre P, Gillot L, Bardet V, Willems L, et al. Autocrine IGF-1/IGF-1R signaling is responsible for constitutive PI3K/Akt activation in acute myeloid leukemia: therapeutic value of neutralizing anti-IGF-1R antibody. Haematologica. 2010;95(3):415-23.

71. Heredia FF, de Sousa JC, Ribeiro Junior HL, Carvalho AF, Magalhaes SM, Pinheiro RF. Proteins related to the spindle and checkpoint mitotic emphasize the different pathogenesis of hypoplastic MDS. Leuk Res. 2014; 38(2):218-24.

72. Khanna-Gupta A. Sumoylation and the function of CCAAT enhancer binding protein alpha (C/EBP alpha). Blood Cells Mol Dis. 2008;41(1):77-81.

73. Maratheftis $\mathrm{Cl}$, Giannouli S, Spachidou MP, Panayotou G, Voulgarelis M. RNA interference of interferon regulatory factor-1 gene expression in THP-1 cell line leads to toll-like receptor-4 overexpression/activation as well as up-modulation of annexin-II. Neoplasia. 2007;9(12):1012-20.

74. Mjahed H, Girodon F, Fontenay M, Garrido C. Heat shock proteins in hematopoietic malignancies. Exp Cell Res. 2012;318(15):1946-58.

75. Qi H, Xiao L, Lingyun W, Ying T, Yi-Zhi L, Shao-Xu Y, et al. Expression of type 1 insulin-like growth factor receptor in marrow nucleated cells in malignant hematological disorders: correlation with apoptosis. Ann Hematol. 2006:85(2):95-101.

76. Sukhai MA, Prabha S, Hurren R, Rutledge AC, Lee AY, Sriskanthadevan S, et al Lysosomal disruption preferentially targets acute myeloid leukemia cells and progenitors. J Clin Invest. 2013;123(1):315-28.

77. van der Putten $K$, Koch B, van Someren E, Wielders J, Ter Wee P, Nagtegaal $E$, et al. The role of renal function loss on circadian misalignment of cytokines EPO, IGF-1, IL-6 and TNF-alfa in chronic renal disease. Neuro Endocrinol Lett. 2011;32(2):148-53. 
78. Kogan SC, Ward JM, Anver MR, Berman JJ, Brayton C, Cardiff RD, et al, Bethesda proposals for classification of nonlymphoid hematopoietic neoplasms in mice. Blood. 2002;100(1):238-45.

79. Mombaerts P, lacomini J, Johnson RS, Herrup K, Tonegawa S, Papaioannou VE. RAG-1-deficient mice have no mature B and T lymphocytes. Cell. 1992;68(5):869-77.

80. Fan AC, Deb-Basu D, Orban MW, Gotlib JR, Natkunam Y, O'Neill R, et al. Nanofluidic proteomic assay for serial analysis of oncoprotein activation in clinical specimens. Nat Med. 2009;15(5):566-71.

81. de la Grange P, Dutertre M, Martin N, Auboeuf D. FAST DB: a website resource for the study of the expression regulation of human gene products. Nucleic Acids Res. 2005;33(13):4276-84.

82. de la Grange P, Gratadou L, Delord M, Dutertre M, Auboeuf D. Splicing factor and exon profiling across human tissues. Nucleic Acids Res. 2010;38(9):2825-38.

83. de la Grange P, Dutertre M, Correa M, Auboeuf D. A new advance in alternative splicing databases: from catalogue to detailed analysis of regulation of expression and function of human alternative splicing variants. BMC Bioinformatics. 2007;8:180.

84. Huang DW, Sherman BT, Lempicki RA. Systematic and integrative analysis of large gene lists using DAVID bioinformatics resources. Nat Protoc. 2009;4(1):44-57.

85. Huang DW, Sherman BT, Lempicki RA. Bioinformatics enrichment tools: paths toward the comprehensive functional analysis of large gene lists. Nucleic Acids Res. 2009;37(1):1-13.

86. Mootha VK, Lindgren CM, Eriksson KF, Subramanian A, Sihag S, Lehar J, et al. PGC-1alpha-responsive genes involved in oxidative phosphorylation are coordinately downregulated in human diabetes. Nat Genet. 2003;34(3):267-73.

87. Subramanian A, Tamayo P, Mootha VK, Mukherjee S, Ebert BL, Gillette MA, et al. Gene set enrichment analysis: a knowledge-based approach for interpreting genome-wide expression profiles. Proc Natl Acad Sci U S A. 2005;102(43):15545-50.

88. Greenberg P, Cox C, LeBeau MM, Fenaux P, Morel P, Sanz G, et al. International scoring system for evaluating prognosis in myelodysplastic syndromes. Blood. 1997;89(6):2079-88.

89. Vardiman JW, Thiele J, Arber DA, Brunning RD, Borowitz MJ, Porwit A, et al. The 2008 revision of the World Health Organization (WHO) classification of myeloid neoplasms and acute leukemia: rationale and important changes. Blood. 2009;1 14(5):937-51.

\section{Submit your next manuscript to BioMed Central and we will help you at every step:}

- We accept pre-submission inquiries

- Our selector tool helps you to find the most relevant journal

- We provide round the clock customer support

- Convenient online submission

- Thorough peer review

- Inclusion in PubMed and all major indexing services

- Maximum visibility for your research

Submit your manuscript at www.biomedcentral.com/submit

C Biomed Central 